\title{
It's About Time: Examining Inequality in the Time Cost of Waiting
}

\author{
Stephen B. Holt* Katie Vinopal ${ }^{\dagger}$
}

June 3, 2021

\begin{abstract}
Time spent waiting for services represents unproductive time imposed on individuals trying to fulfill basic needs. While qualitative and ethnographic work has found that income disparities also translate into disparities in time kept waiting for services, little evidence exists to confirm the scale and extent of socioeconomic differences in waiting time. We use time diary data from the nationally representative American Time Use Survey (ATUS) to estimate the difference between high- and low-income people in time spent waiting for basic services. We find that, relative to high-income people, low-income people are 3 percentage-points more likely to spend time waiting on an average day and their waiting spells are 12 minutes longer on average. The income gap in waiting time cannot be explained by differences in family obligations, demographics, education, work time, or travel time. Further, we find that high-income Black people experience the same higher average wait times as low-income people regardless of race. Our results suggest socioeconomic and racial inequalities in neighborhood quality, work schedule flexibility, and access to services exacerbate inequality in daily quality of life and the availability of productive time.
\end{abstract}

Keywords: Time Use, Inequality, Waiting Time

JEL Codes: I14, I32, D12

\footnotetext{
*Corresponding author. Email: sbholt@albany.edu. University at Albany, SUNY, Rockefeller College of Public Affairs and Policy.

†The Ohio State University, Glenn College of Public Affairs.
} 


\section{Introduction}

Autonomy over the allocation of one's time - to care for oneself and one's family, to work for pay, and to engage in leisure — is essential to well-being and flourishing. Yet previous research suggests that the degree of this autonomy is unequal among groups in society in ways that enforce and reproduce social inequality (e.g., Cohen, 2018; Gee et al., 2019).

One way to investigate this inequality is by studying time spent waiting for goods and services. Waiting is generally unproductive and often unpleasant, and takes time away from life-enhancing endeavors such as paid work, time with family, health-related activities, and leisure time. In his seminal work on the subject, Schwartz (1974) concludes that "waiting is patterned on the distribution of power in a social system," and, more generally, that "far from being a coincidental by-product of power, then, control of time comes into view as one of its essential properties."

Indeed, research across academic disciplines suggests likely disparities in time spent waiting for goods and services by socioeconomic status, race and ethnicity, and gender. For example, people who are lower-income or part of a racial minority group are more likely to live in neighborhoods with more limited access to grocery stores, drug stores, laundry, and banks (e.g., Dunham, 2018; Hegerty, 2016; Schuetz et al., 2012), and Medicaid recipients wait longer to see a healthcare provider (Oostrom et al., 2017). Having low income also limits individuals' ability to pay for convenient, time-saving services (Cohen, 1998), such as grocery delivery, and increases individuals' interaction with burdensome government bureaucracies (Herd and Moynihan, 2019; Ray et al., 2020). Yet, with some notable exceptions using an ethnographic approach (e.g., Auyero, 2011; Roy et al., 2004), empirical work on this social patterning of waiting is lacking.

In this paper, we provide deep, descriptive evidence from 17 years of nationally representative time diary data of differences in time spent waiting by socioeconomic status, race, gender, and the intersections of these characteristics. In doing so, we hope to shed more light on a less studied aspect of inequality and inform policies and practices that enhance 
time autonomy for all people.

We find among individuals using common services (e.g., shopping, medical care, or household, legal, financial, or educational services for household children and adults), low-income people wait an average of 73 hours per year more than high-income people. An income gap is also observed in time spent waiting for medical care and shopping. The gap shrinks but remains practically significant after controlling for a host of demographic characteristics. Further, this gap likely understates the true extent of this disparity, given that high-income people are more likely to avoid waiting entirely. Additionally, we find large disparities by race for Black people: while wealthier White, Asian, and Latino(a) people all face less waiting time than their wealthier, same-race peers, wealthier Black people wait as long or longer than lower-income Black people and wealthy non-Black people.

Our analysis offers two primary contributions to the literature on inequality. First, our use of time diary data tied to detailed household information allows us to provide the first large-scale confirmation of the socioeconomic gap in time spent waiting for common and necessary services. Moreover, the data enable us to investigate the role of household, transit, race, gender, and schedule flexibility in the income-based gap in waiting time. Second, our analysis raises an important, novel aspect of income inequality for further research and policy attention - unproductive waiting time. We posit that income-based gaps in time spent waiting for basic services captures a symptom of structural inequalities, experienced individually, that likely reinforce economic inequality through unevenly distributed lost productivity.

\section{Literature Review}

\subsection{Time inequality}

Time is valuable resource; having enough of it and autonomy over it is fundamental to human health, productivity, and wellbeing. However, previous research has suggested that time operates like a privilege, much like income or wealth, and is socially determined such 
that disadvantaged groups - by race, class, and gender - have less free time and more time scarcity (Cohen, 2018; Gee et al., 2019).

This "time inequality", or inequality in the autonomy over one's time, is important to understand, as it reflects the differences in how society values people's time on the basis of race, class, or gender, and it has direct consequences for wellbeing, especially when paired with other disadvantages, such as income poverty. For example: delays in receiving medical care result in worse health outcomes, waiting in long lines reduces individuals' ability to vote, and dealing with prolonged bureaucratic processes to receive government benefits reduces other productive or enjoyable time. Closely related is research on "time poverty", which is defined differently by different authors, but is generally related to having insufficient time for rest and leisure, after accounting for time spent in necessary and committed time, such as paid and unpaid labor (Bittman, 2002; Kalenkoski et al., 2011; Vickery, 1977; Williams et al. 2016, Zilanawala, 2016).

Time inequality also likely serves as a mechanism for other observed inequities. Researchers have documented the ways in which time is an important social determinant of health (Strazdins et al., 2011), and thus time inequality likely contributes to observed health inequality. Time is needed for physical health promoting activities, such as exercise, sleep, preventative care, and healthy food choices (Jabs and Devine, 2006), as well as mental health promoting activities, such as maintaining social relationships, caring for loved ones, and managing stress (Gee et al. 2019). Additionally, both income and time scarcity are related to reduced physical activity and less healthy diets (Venn and Strazdins, 2017). And generally, a lack of time is linked to stress and illness (Gee et al., 2019). Time inequality likely also contributes to income inequality, since spending time in necessary but unproductive activities (i.e., waiting for goods and services) takes away time spent in paid work.

Social patterning in time autonomy and scarcity results from a number of mechanisms. First, higher-income jobs often come with more job flexibility than lower-income ones Kossek and Lautsch, 2018). Thus, higher-income employees are more likely to have the ability to, 
for example, take a long lunch break or paid leave to accommodate a doctor's appointment or a parent-teacher conference. A lower-income employee is less likely to have paid leave or any flexibility over their break time, and may have to take an entire day off work to accommodate necessary appointments. Relatedly, pay structures — salary versus hourly pay - are correlated with income and dictate the opportunity cost of taking time off work for such appointments. Higher-income, salaried workers suffer no economic cost from attending an appointment during work hours, whereas a lower-income, hourly worker loses out on earnings. Since women and people of color are more likely to be employed at less flexible, hourly jobs, this also has implications for gender and racial time inequality (Loprest et al., 2009).

Second, higher-income people have the ability to pay for convenience in ways lower-income people cannot afford (Cohen, 1998). In other words, money allows one to pay for time. This broad observation may manifest in ways that produce relatively small time savings — such as ordering grocery delivery and avoiding bargain hunting - or very large ones, such as paying for elder care for an aging parent instead of providing it oneself.

Third, people in more disadvantaged social positions are more likely to interact with the government more frequently and in more burdensome ways than more advantaged people (Herd and Moynihan, 2020). Again, this observation is exemplified in numerous ways. For example, a person making less than $\$ 20,000$ per year and who is likely to claim the Earned Income Tax Credit is more likely to be audited - a time-consuming and stressful process - than a person making more than $\$ 400,000$ per year (Kiel and Eisinger). More routinely, receipt of means-tested benefits generally, such as Medicaid, the Supplemental Nutrition Assistance Program (SNAP), Temporary Assistance for Needy Families (TANF), housing assistance, or childcare subsidies, often require high administrative burdens: significant time spent on paper work, in government office waiting rooms, and on the phone dealing with bureaucracy (Herd and Moynihan, 2019). The costs of failing to shoulder this burden can be huge. For example, depending on which state one lives in, failing to respond to a letter promptly may 
put a family at risk of losing Medicaid (Badger and Sanger-Katz 2021), potentially causing harm to health and finances, and necessitating a prolonged re-application process. Further, administrative burdens across various domains, including the social safety net, immigration, and voting, have been used to "normalize and facilitate racially disparate outcomes from public organizations that promise fair and equal treatment" (Ray et al., 2020). For example, in the 2016 U.S. presidential election, residents of entirely black neighborhoods waited nearly $30 \%$ longer to vote than residents of entirely white neighborhoods. They were also $74 \%$ more likely to spend more than 30 minutes at their polling place (Chen et al., 2019). Other research has shown similar disparities in voting wait times (Pettigrew, 2017).

Encounters with the criminal justice system is also socially patterned, such that people living in lower income and, especially, minority communities are more likely to be stopped (Pierson et al., 2020), arrested (Engel and Calnon, 2004), and incarcerated (Western and Pettit, 2010; Wakefield and Uggen, 2010). Resolving these interactions - disputing parking tickets, finding legal representation, appearing in court, sitting in jail for minor offenses takes significant time.

Structural racism and class discrimination are at the root of other sources of time inequality as well, as discussed by Gee and colleagues (2019). For example, in a field experiment, Kugelmass (2016) finds that middle-class mental healthcare seekers were offered appointments from psychotherapists at nearly three times the rate of their working-class counterparts. Further, among middle-class help-seekers, Black seekers were less likely than white seekers to be offered an appointment (Kugelmass, 2016). This suggests it may take significantly more time for working-class and Black individuals to find necessary mental health care because of the bias of practitioners. Another example comes from the housing market: Massey and Lundy (2001) show that Black-sounding callers took twice as long to find an apartment compared to white-sounding callers. As a final example, research has found that race, having Medicaid or no insurance, and living in a low-education community are among the predictors of a longer wait time to breast surgery among breast cancer patients 
(Liederbach et al., 2015).

Fifth, lower-income people are less likely to have efficient access to efficient goods and services. For example, Medicaid patients have reduced access to care compared to privately insured patients (Hsiang et al., 2019) and longer doctor's waiting room times, largely due to the number and types of practices and providers that accept Medicaid insurance, given its reimbursement rate is generally lower than private insurance (Oostrom et al., 2017).

Neighborhoods also matter. Neighborhoods play an important role in shaping intergenerational poverty and the children of families who move to lower-poverty neighborhoods experience significantly better economic outcomes in adulthood (Chetty et al., 2016; Chetty and Hendren, 2018). Access to reliable and high-quality services likely serve as one mechanism through which neighborhoods affect poverty. Lower-income and racial minority neighborhoods are more likely to be located in food deserts - areas where people have limited access to a variety of healthy and affordable food (Dutko et al., 2012) — thus requiring residents spend more time finding transportation and traveling to buy their groceries or rely on less healthy but nearby alternatives (Cooksey-Stowers et al., 2017). While research on the systematic differences in the location of food outlets has received the most attention in the literature, other work has demonstrated that retail patterns more generally vary by neighborhood income: high-poverty neighborhoods have lower retail employment density for supermarkets, drug stores, food service, and laundry (Schuetz et al., 2012). Other work has shown that banking deserts - areas without access to a physical bank branch — are more likely to be poorer and have a higher proportion of Black and Latino(a) residents (e.g., Dunham, 2018; Hegerty, 2016).

Time inequality due to differences in the built environment and neighborhood characteristics are further exacerbated by transportation inequality. Access to an automobile plays an important role in the economic outcomes of low-income household, yet low income and racial minority households are less likely to own a reliable car compared to higher income and white households (Pendall et al., 2014; Baker et al., 2020; Quinton, 2014). Public transit 
plays an important role in increasing less advantaged groups' access to goods, services, and jobs, but bus and subway riders have less control over departure, arrival, and travel times and locations, resulting in more time wasted during the day.

Finally, a large literature documents gender-based time inequality, especially since the emergence of dual-earner households. Women in heterosexual partnerships still tend to take on significantly more household and childcare duties than men, despite also working for pay, and therefore have less free time (e.g., Bittman and Wajcman, 2000; Harvey and Mukhopadhyay, 2007; Hochschild and Machung, 2012; Kalenkoski et al., 2011; Mattingly and Blanchi, 2003; Sayer, 2005; Vickery, 1977). These gender disparities have been recently exacerbated by the COVID-19 pandemic (Bauer et al., 2021). Research has also shown that women have different transport and travel patterns than men, with women combining household tasks into one, longer journey, and men more likely to make a single-purpose trip (Turner and Grieco, 2000). These differences in travel patterns are both born out of and contribute to gender time inequality, and are compounded for lower-income women who are more likely to rely on public transportation (Turner and Grieco, 2000). Further, even when total time in paid and unpaid labor are determined to be relatively equivalent across gender, the quality of women's leisure time is poorer: more likely to be interrupted and to be "contaminated" with unpaid work (Bittman and Wajcman, 2000). These gender differences are likely compounded for low-income women and especially low-income mothers (e.g., Kendig and Bianchi, 2008; Warren, 2003. In fact, when measuring poverty as a function of both income and time, poverty rates are likely much higher, especially for working, single parents (Douthitt, 2000).

\section{$2.2 \quad$ Waiting}

Studying time spent waiting for goods and services is one way to better understand one aspect of overall inequality in autonomy over the allocation of one's time by socioeconomic status, race, and gender. If given the choice, most people would not choose to wait. Waiting 
itself is generally unproductive; at best it is boring or unpleasant, and at worst, as in the case of waiting for urgent medical care or waiting an excessively long time to vote, it may be dangerous, disempowering, or Kafkaesque. For example, research has found that longer wait times to see healthcare providers are associated with less patient satisfaction, less confidence in the care provided, and lower perceived care quality (Bleustein et al., 2014).

Sociologists have long argued that the distribution of waiting time corresponds to the distribution of power in society, and that waiting itself is can be used as a tool of domination (Auyero, 2011; Schwartz, 1974). As Schwartz (1974) puts it, to be kept waiting "is to be the subject of an assertion that one's own time (and therefore, one's social worth) is less valuable than the time and worth of the one who imposes the wait." However, this observation has received limited empirical attention, with the exception of work by Javier Auyero. In his ethnographic account of poor people's waiting in welfare offices in Buenos Aires, Auyero (2011) finds that these experiences convey "the implicit state request to be compliant clients." In other words, the subordination involved in becoming a welfare recipient is "created and re-created through innumerable acts of waiting" (Auyero, 2011). We expand the empirical evidence of socioeconomic gaps in waiting time using cross-sectional time diary data from the United States.

\section{Data}

We investigate the socioeconomic gap in time spent waiting for services using data from the American Time Use Survey (ATUS). The ATUS collects retrospective time diary data from a nationally representative subsample drawn from respondents to the Census Bureau's Community Population Survey (CPS) each year. When completing the time diaries, one respondent aged 15 or older per household reports their activities during the previous 24hours in 15-minute increments. Three features of the ATUS make the data appropriate for the purposes of our analysis. First, time diaries do not direct respondent attention to any 
particular activity, thereby reducing the potential biases of framing, interpretation, social desirability, or recall common in conventional survey data (Juster and Stafford, 1991). Second, the ATUS links respondents to rich CPS data regarding their household characteristics, demographics, education, and socioeconomic status (SES), which allow us to compare timeuse patterns in an average day across people in different economic circumstances. Finally, the ATUS includes waiting time associated with various activities separately from time spent in said activity.

\subsection{Dependent Variable}

We focus our analysis on the average amount of time spent waiting for common services, in minutes, in a typical 24-hour period. We include time spent on waiting associated with shopping; medical care for the respondent, household children and adults, and non-household children and adults; household services (e.g., maintenance, lawn services, etc.); legal services; financial services; educational services for the respondent or household and non-household children; government services; and personal care services (e.g., salons, barbers, etc.). We take the sum of time spent waiting on common services in a 24-hour period as our primary outcome of interest. We complement our analysis with an examination of time spent waiting on medical service for respondents and their household children and time spent on waiting associated with shopping, two core services for which inequality in waiting time suggests inequality in treatment, access to quality services, or inequality in neighborhood conditions.

\subsection{Independent Variables}

Our primary independent variable of interest is household income. The CPS collects selfreported annual household income for each respondent and provides a categorical measure of household income that is top-coded at an annual household income of $\$ 150,000$ or more per year. For our main analysis, we use a seven category measure of household income that ranges from $\$ 20,000$ or less to $\$ 150,000$ or more in annual income. For the purposes 
of our analysis, we define "low-income" as households with income of $\$ 20,000$ or less and "high-income" using the top-coded category of $\$ 150,000$ or more.1.$^{1}$

Of course, other factors might systematically differ by both income and the factors that contribute to time spent waiting for services. For instance, transit or hours spent working might contribute to the socioeconomic gap in wait time. Fortunately, in addition to providing time spent working throughout the day, the ATUS includes a breakout of travel time associated with specific activities - including the activities for which respondents wait.2 We measure travel time as the sum of all time spent on travel associated with the activities included in our measure of waiting time $3^{3}$

We also include measures for family composition, demographics, education, and an indicator for whether the respondent is unemployed. We measure family composition with an indicator for whether the respondent is married, whether the respondent has a child 2 years old or younger in their household, and the number of children 17 or under in the household. We capture education with mutually exclusive indicators for whether the respondent's highest educational attainment is less than a high school diploma, a high school diploma, some college, and a four-year college degree or more. Finally, demographics include gender (male or female), race (Black, White, Asian/Pacific Islander, Hispanic, Native American, multiple races, and other race), and age. Demographic and family factors might shape the probability that a person needs to engage in some activities associated with wait times or might shape where a person lives and the mix of service quality in their neighborhood.

\footnotetext{
${ }^{1}$ The federal poverty line for an individual in 2021 in the continental U.S. is $\$ 12,880$ with an additional $\$ 4,540$ for each additional person in the household. In 2003 , the poverty line for a family of four was $\$ 18,400$ in the 48 contiguous states and the District of Columbia. See https://aspe.hhs.gov/poverty-guidelines for more detail.

${ }^{2}$ The ATUS associates travel time according to the activity performed immediately following the travel. For instance, if a person stops at a shop on the way to work, travel to the shop is coded as "travel associated with shopping" and the travel from the shop to work is coded as "travel associated with working." While the coding rule adopted by the ATUS carries potentially substantial implications for estimating commute times to and from work (Kimbrough, 2019), estimates measuring travel-time for specific activities besides work is not meaningfully influenced by the ATUS coding rule (Allard, 2018).

${ }^{3}$ This includes travel associated with: personal care services, household services, caring for household members, caring for non-household members, education, childcare services, financial services, legal services, medical services, shopping, and government services.
} 
Finally, we also include a measure for whether someone lives in the metropolitan statistical area (MSA) of a major city $\left.\right|^{4}$ People living in denser cities may have more options available nearby for services; however, denser cities may also increase wait time due to higher demand for services.

$$
<<<\text { Table } 1 \text { about here }>>>
$$

Table 1 summarizes the ATUS sample, both overall and separately by household income. Columns 1 through 3 include all time diaries for the full sample and separately by low- and high-income respondents. Columns 4 and 5 restrict the sample to low- and high-income households who report non-zero time spent receiving services associated with waiting, while columns 6 and 7 restrict the sample to diaries with non-zero waiting time. As shown in column 1, the average American spends a little less than 2 minutes waiting for services on an average day; however, that is largely due to the "pile-up" of zeroes attributable to, in part, some respondents not using services on the diary day and therefore not waiting. Among those with some waiting time for services on the diary day, the average person spent nearly 40 minutes waiting for services throughout the day. As columns 2 and 3 show, on days in which some time is spent waiting for services, low-income people wait over 15 minutes longer for services than high-income people (44.69 minutes to 28.89 minutes).

Perhaps unsurprisingly, low-income people also differ systematically from high-income people in other observable characteristics. Relative to high-income people, people from lowincome households are more likely to be Black or Latino(a), female, unmarried, and have lower educational attainment, all characteristics that may provide insights into what drives the income-gap in waiting time. For instance, given the association between race and income, the gap may instead be fully explained by race and therefore reflect racial discrimination among service providers rather than policy or neighborhood related factors. Similarly, if education explains the income gap in wait time, social networks and human capital might

\footnotetext{
${ }^{4}$ The Census Bureau identifies 366 MSAs. An MSA includes both the central city and adjacent communities that have a high degree of economic and social interdependence and interaction.
} 
explain the difference in wait times between low- and high-income people. That is, highly educated people might also better identify bad service providers or learn how to navigate services in ways that reduce their time spent waiting.

Finally, one potential concern is that diary days on which people report using services associated with waiting or some amount of waiting time come from a less representative sample. However, comparing columns 4 and 5 (6 and 7) with columns 2 and 3 ameliorates such concerns. Low- and high-income people using some services or spending some time waiting have similar demographics, education, and family characteristics on average to lowand high-income households in the full sample. In diary days with non-zero waiting time, men are slightly under-represented and high-income people who did not graduate high school are over-represented.

\subsection{Methods}

We aim to descriptively investigate the size of income-based gaps in time spent waiting for necessary and common services, as well as some of the potential explanations for these gaps. We adopt a straightforward linear model of waiting time $(Y)$ of person $i$ :

$$
Y_{i}=\alpha+\beta S E S_{i}+\gamma X_{i}+\tau+\varepsilon_{i}
$$

where $S E S$ represents socioeconomic status measured with indicators for each category of household income described previously; $X$ represents a vector of controls for demographics, education, family composition, unemployment status, MSA status, and travel and work time; and $\tau$ represents day of week, month, and year time trends. In equation (1), $\beta$ represents our parameter of interest and captures the difference in waiting time experienced by highand low-income households after accounting for differences in observable characteristics and time trends in waiting time. Important for our purposes, as various $X$ enter the model,

the resulting change in $\beta$ provides insights regarding how much of the SES gap in time 
spent waiting can be attributed to other factors that differ by SES. Finally, we estimate two augmentations of equation (1). In one extension, we add state fixed-effects to account for possible variation in SES gaps in waiting time driven by unobserved state-specific, timeinvariant attributes. In another, we replace time spent waiting with a binary indicator equal to 1 if the respondent did not spend any time waiting during the diary day. Using an indicator for no waiting time allows us to examine the SES gap on the extensive margin of waiting in addition to comparing total time spent waiting.

We estimate equation (1) using OLS with standard errors clustered at the state-level and take that as our preferred estimates for ease of inference $5^{5}$ We weight all regressions using BLS provided sampling weights that account for the unequal sampling probability of subgroups, days, and months of time diaries.

\section{Results}

\subsection{Main Effects}

We begin with a look at the SES gap in the likelihood a person has no wait for services, restricting the sample to diary days with at least some time spent using the services associated with waiting. ${ }^{6}$

$$
<<<\text { Table } 2 \text { about here }>>>
$$

\footnotetext{
${ }^{5}$ See Table A4 for average partial effects (APE) estimated using Tobit regression models to account for the left censored nature of time data and the "pile-up" at zero. Sturman (1999) shows that OLS is more robust to Type II errors than count models, even in with a pile-up at zero. Similarly, Stewart (2013) shows OLS is more robust that Tobit when the measurement error is attributable to the sampling of days inherent to time diary data. Table A2 and Table A3 report the APE of Type 1 Tobit, two-limit Tobit, and Poisson regression to demonstrate robustness to choice of estimator.

${ }^{6}$ See Table A.1 for results with no sample restrictions and including diary days with 0 time spent waiting for services. Notably, the SES gap between the lowest and highest income households remains significant. The patterns as controls enter the model also remain consistent. We focus here on non-zero waiting time to compare high- and low-income experiences with waiting when it occurs. Table A5 replicates the analysis and restricts the sample to observations who reported non-zero time spent using services included in our waiting time to remove respondents reporting 0 wait time due to not engaging with services on the diary day. Again, the results are consistent. Finally, Table A6 replicates the linear probability models in Table 2 with logistic regressions to account for the binary nature of the outcome. The results are strikingly similar.
} 
When spending some amount of time pursuing basic services, high-income people may be more likely to avoid waiting entirely. Table 2 presents estimates of linear probability models (LPM) examining the SES difference in the probability of spending no time waiting for service among people who used services during the diary day. Column 1 shows that low-income people are 3 percentage points less likely to have no waiting time when using basic services. Column 4 demonstrates that at least some of the gap can be attributed to differences in time spent working. Finally, columns 6 and 7 show that after accounting for demographics, education, unemployment status, and state fixed-effects, low-income people are still more likely to have some waiting time when consuming services. The difference is small, but remains statistically significant. Moreover, the change in the estimate suggests that demographics, such as race and gender, play a role in subjection to wasteful time spent waiting for services.

$$
<<<\text { Table } 3 \text { about here }>>>
$$

Table 3 presents OLS estimates of equation (1), focusing on the parameter of interest the SES gap in the amount of time spent waiting for services - and columns 2 through 7 add controls for observable characteristics. As column 1 indicates, on diary days when people spend some time waiting for service, people at the bottom of the income distribution spend 12 more minutes waiting for service than people at the top. This suggests in an average week, people from low-income households spend about an hour more waiting for the same set of services than people from high-income households - a gap that would aggregate to about 73 hours per year. The loss over nearly two full-time work weeks to additional waiting time for basic services underscores the extent of inequality low-income households face in quality of life daily.

One possible explanation for the discrepancy is that high-income people live in denser cities where they may have more service options for both public and commercial services. Column 2 controls for living in an MSA, which includes the largest cities in the U.S. and their adjacent communities, and suggests differential sorting by SES into more urban areas 
only accounts for about $5 \%$ of the gap in time spent waiting. Of course, MSAs include wide geographic area and services differ systematically by neighborhood. Another possibility is that quality service options cluster in neighborhoods farther from low-income people or the reliance on public transit means low-income people schedule slack time in their appointments to account for unreliable transportation schedules. Column 3 controls for waiting time associated with time spent traveling to use services. Differences between low- and highincome people in time spent traveling to use services only explains about $2 \%$ of the SES gap in time spent waiting.

In column 4, we add controls for time spent working during the diary day. Generally, low-income workers have less control over their work hours and less flexibility in their work schedules. As a result, some of the gap in waiting for services might be driven by highearners' ability to schedule service appointments during the day or when they are not working to receive services during non-peak hours. After accounting for time spent working on the diary day, the SES gap in wait time decreases by about 25\%, which suggests work schedule flexibility explains meaningful proportion of the SES gap in time spent waiting for services. Still, a substantial gap remains. As shown in column 6, adding controls for education, unemployment status, race, gender, age, marital status, and household children, low-income people spend more than 7 additional minutes waiting for service relative to the wait time of their high-income peers. Finally, the gap remains after accounting for state-specific patterns in waiting time.

\subsection{Waiting for Specific Services}

We have focused our analysis on total time spent waiting for any basic services, including services less commonly observed in an average diary day such as legal or government services. Two of the services most commonly used, and most commonly associated with waiting time, are medical services and shopping (including grocery shopping). Given the importance of access to medical care and shopping in daily life, a waiting gap for these services provides 
insight into inequality in quality of life when meeting basic needs in a typical day. We restrict the sample to diary days with non-zero waiting time for these two basic services to examine whether the SES gap persists.

$$
<<<\text { Figure 1 and Figure 2 about here }>>>
$$

Figure 1 presents the marginal effects of SES on total time spent waiting for medical service among people who spent some time waiting for medical care for themselves or their children. As the figure shows, accounting only for time trends, low-income people spend significantly more time waiting for medical services. On an average day when both a highand low-income person wait for medical care, the poorer person waits an average of 46.28 minutes while the wealthier person waits an average of 28.75 minutes - a $38 \%$ difference in time spent unproductively waiting to be seen. Even after controlling for family characteristics, employment status, travel time associated with medical care, and time spent working, wealthy people spend considerably less time waiting for medical care on average (45.06 minutes versus 33.58 minutes).

Figure 2 conducts the same analysis for time spent waiting while shopping. As with waiting for all services and waiting for medical care, among shoppers kept waiting for some amount of time, low-income people wait longer on average and the difference is statistically significant. Accounting for only year, month, and day of week effects, low-income people spend about 24 minutes waiting while shopping, including for basic necessities like groceries, while wealthier people face an average wait of 15 minutes when they have to wait. Differences between high- and low-income people in travel time, work time, family characteristics, and unemployment status only account for about 2 minutes of the nearly 9 minute gap in time spent waiting while shopping for goods. The conditional difference is still 6.67 more minutes that people living at or near the poverty line spend waiting while shopping relative to wealthier people in an average wait.

Even small differences in average wait time add up throughout the year. A low-income household with a regular need for medical care that involves two appointments a month - 
such as seeing a doctor or picking up a prescription for themselves or their children - can expect to spend nearly 5 additional hours per year in waiting rooms. Similarly, a low-income household that shops for goods 3 times a week with some waiting time can expect to spend 16 additional hours per year standing in line at shops and grocers in comparison to people in the wealthiest households. Even beyond exacerbating inequity, the waiting gap carries two important policy considerations. First, wait times might alter behavior. If medical service appointments take more time, low-income households may put off seeking medical help until health problems become severe and more costly to ameliorate, especially if low-income households face less schedule flexibility. When grocery shopping involves burdensome wait times, low-income households may consume more processed foods to reduce their number of trips to the store - possibly leading to less healthy eating choices. Second, income-based gains in waiting time during a typical waiting spell for services suggests different service quality availability in neighborhoods where low- and high-income people live.

\subsection{Race differences in waiting by SES}

As discussed further above, we might also expect to see differences in wait time by race for a number of reasons, including a legacy of housing discrimination that has sorted Black people into underserved communities with overburdened services, ongoing racism in access to high-quality medical services, and increased contact with burdensome government processes, among others. We examine differences by both race and class in time spent waiting for services by estimating both the likelihood to be kept waiting for service and time spent waiting for service separately by race and class. Given the visibility and salience of race, a person's race might shape their time spent waiting for services independently of SES.

$$
<<<\text { Figure } 6 \text { about here }>>>
$$

Figure 6 depicts the probability that someone using basic services had to wait for service separately by race and SES. Two results emerge from the patterns in Figure 6. First, for 
White and Black Americans, class seems to play a larger role in determining the likelihood of waiting for service than race. Low-income White and Black Americans are both more likely to wait when seeking services than their wealthier same-race peers. Second, for Latino(a) and Asian Americans, race seems more salient. Both low- and high-income Latino(a) Americans share a higher likelihood of waiting for services than White Americans in the same income bracket. That is, Latino(a) Americans do not seem to receive the same drop in their exposure to waiting that comes with wealth that White and Black Americans receive. On the other hand, Asian Americans are the least likely to experience any waiting for services regardless of income.

$$
<<<\text { Figure } 7 \text { about here }>>>
$$

However, examining time spent waiting for services when waiting occurs illustrates the link between race and time spent waiting. Figure 7 displays the average time spent waiting separately by race and SES. As the figure indicates, wealthier White, Asian, and Latino(a) people all face significantly less waiting time when waiting for services than their less welloff same-race peers. However, when wealthier Black people wait for services, they wait as long or longer than lower-income Black people. Moreover, the difference in time spent waiting for service between wealthy Black people and wealthy non-Black people is statistically significant. For instance, while wealthier White people face an average wait time of 28 minutes while wealthier Black people face a 54 minute average wait time.

Together, the results from the analysis in Figure 6 and Figure 7 suggest a few patterns in the relative roles of race and SES in waiting for services. Wealthier Black people might be less subject to waiting on the extensive margin because income allows some people to seek more high quality services or pursue strategies that avoid waiting entirely (e.g., online retail for shopping or paying for someone else to wait in their place). However, when waiting does occur, wealthier Black people do not receive the same time-saving attention from service providers that wealthier non-Black people receive. When seeking basic services, Black Americans face a double disadvantage due to historic and current discrimination: they are more 
likely to be poor and therefore subject to higher wait times driven by SES inequality and Black Americans experience higher average wait times independent of income. That even wealthier Black Americans do not see lower wait times could be a function of systematic discrimination in treatment, a symptom of Black communities receiving less financial support, leaving services overburdened and under-resourced, or a combination of both discriminatory treatment and structural disadvantage.

\subsection{Gender differences in waiting by SES}

Gender may also play an important role in time spent waiting for services. For instance, as noted previously, women - particularly mothers - often face disproportionate time poverty as parental and household obligations often fall on them. Consequently, women may be subjected to more time spent waiting than men and the gender gap may vary by SES. We investigate this dynamic by examining the gender gap in the likelihood to use common services associated with waiting, compare the likelihood to wait at all among men and women using services in a typical day, and finally compare the time men and women spend waiting for service when waiting occurs.

$$
<<<\text { Figure } 3 \text { about here }>>>
$$

We begin by estimating a linear probability model with an indicator for whether the respondent spent any time using common services during the diary day. Intuitively, a gender based gap in waiting time might simply reflect a gender disparity in using the services related to running a household. On the other hand, if waiting reflects class-based barriers to quality services - such as schedule autonomy or neighborhood quality - we might expect time spent waiting to break along SES lines regardless of gender and despite gender disparities in service use. Figure 3 presents the probability of using common services in a typical day separately by gender, SES, and parental status. Notably, within SES, women are more likely than men to spend some time using common services in a typical day. Low-income women are 3 
percentage points more likely than low-income men and high-income women are 6 percentage points more likely than high-income men to use common services. Among parents, the gender gap is similar, though slightly larger for low-income parents ( 5 percentage points). Consistent with extant work (e.g., Kalenkoski et al., 2011), we find women are more likely to be spending time on common services like shopping, childcare, health care, education, and the other services related to household needs included in waiting time used in our primary analysis. The gender gap remains even after accounting for traveling, worktime, and unemployment status.

$$
<<<\text { Figure } 4 \text { about here }>>>
$$

Since women - and especially mothers - disproportionately use basic services, a gender gap in waiting time could be acutely burdensome for low-income women. We examine this both at the extensive margin, using the probability of waiting at all when using services, and the intensive margin, using the length of an average wait for services. Figure 4 displays the probability of having some wait time when using basic services separately by gender and SES while accounting for time spent traveling to services, time spent working, unemployment status, and MSA status. The analysis bares out two important results. First, within SES, men and women face a similar probability of waiting for services. Among low-income people, men are 1 percentage point less likely to wait when using services than low-income women. However, among parents and high-income men and women, the gender gap within class is small and not statistically significant. Second, across SES, we again see that low-income men and women are more likely to wait for service than their high-income peers - a 2 percentage point difference both overall and among parents.

$$
<<<\text { Figure } 5 \text { about here }>>>
$$

While we see little evidence of gender difference in the likelihood to experience waiting for service when using services, Figure 5 suggests a gender gap in time spent waiting that 
favors high-income women. Figure 5 depicts the average time spent waiting for services, in minutes, for diary days that reported at least some time waiting for service, which accounts for the unequal probability between men and women of using services to compare time spent waiting. Perhaps surprisingly, we find that overall, men spend more time waiting for service than women on average within SES. When waiting for service, low-income men spend about 6 more minutes than low-income women waiting for service (46 minutes versus 40 minutes), though the difference is not statistically significant. Meanwhile, high-income men spend about 12 more minutes waiting for services than high-income women (42 minutes versus 30 minutes). Moreover, high-income men have an average wait time (42 minutes) similar to low-income men (46 minutes) and low-income women (40 minutes). Finally, high-income mothers maintain a significantly lower wait time, on average, relative to other parents.

Overall, we find gender plays a nuanced role in time spent waiting. While we find lowincome women are slightly more likely to spend some time waiting for basic services relative to low-income men, there is little evidence of a similar gender gap among high-income people. Moreover, the low-income gender gap in waiting on the extensive margin is likely a function of the gender gap we observe in household and care-taking responsibilities. Finally, among those who wait, both low- and high-income women tend to face lower average wait times then men in the same SES.

\subsection{Time of day differences in waiting by SES}

Schedule flexibility presents another avenue through which inequity in time spent waiting might operate. As discussed above, high-income workers often have more autonomy in their professional lives and face fewer penalties or barriers to taking time off work during the work week to manage other personal matters. Work schedule autonomy might allow for optimizing

appointment scheduling during non-peak hours when many others must work. Intuitively, if schedule autonomy drives the income gap in waiting time, we anticipate wait times during high-demand hours - before and after the workday - to be distributed evenly between high- 
and low-income people. In the case of similar wait times during peak hours, an overall gap in waiting time could be driven by high-income individuals scheduling services off-peak hours and not due to differential treatment or differential service quality. We break the time of day into morning (5 am to 10:59 am), lunchtime (11 am to 1:59 pm), afternoon (2 pm to 5:59 pm), and evening (6 pm to midnight).

$$
<<<\text { Figure } 8 \text { and Figure } 9 \text { about here }>>>
$$

We begin by estimating linear probability models of the likelihood someone spends at least some time waiting for for service at each time of day separately by income and by weekdays versus weekends. Figure 8 and Figure 9 present the average probability a person has to wait by time of day during the week (Figure 8) and on weekends (Figure 9). Notably, during the week, low-income people are slightly more likely to wait for services in the morning and during lunch (about 1 percentage point), but later in the day and throughout the weekends, the probability of waiting for service does not meaningfully differ by SES.

$$
<<<\text { Figure 10 and Figure 11 about here }>>>
$$

Figure 10 and Figure 11 present the estimated average time spent waiting for services by income and time of day on weekdays and weekends respectively. Notably, during the week, when waiting for service, low-income people spend much more time waiting in the mornings and evenings than their wealthier peers who are also waiting for service. For instance, in the morning, a low-income person can expect to spend nearly double the amount of time waiting for service than a wealthier person (50 minutes versus 26 minutes). In the evening, the SES gap in time spent waiting is more than double (37 minutes versus 15). Meanwhile, as Figure 11 shows, low-income people face a longer wait time at every time of day on the weekends.

Collectively, the results suggest that while schedule autonomy may play a role (lowincome workers are indeed more likely to be waiting before work in the mornings), they do 
not fully explain the SES gap in time spent waiting. For instance, even in the mornings and evenings, when demand for services might be highest, wealthier people face shorter waits. Similarly, on the weekends, wealthier people face shorter waits at any time of day. Moreover, the gaps reflect a troubling inequality - low-income people lose more of their nonwork time in the mornings and evenings, time which could be spent in leisure or with family, to unproductively waiting for basic services. Instead of rejuvenating on weekends or after work hours, low-income people have more of their time wasted trying take care of basic needs. The patterns suggest the waiting time gap is unlikely to be explained entirely by schedule autonomy and instead a function of other inequalities, such as inequity in neighborhood services or in public services provided to low-income people.

\section{Discussion and Conclusion}

In summary, we find that when spending some amount of time pursuing basic services, highincome people are more likely to avoid waiting entirely and, on average, people at the bottom of the income distribution spend 12 more minutes per day - or 73 hours per year — waiting for services than people at the top. This gap shrinks but remains practically significant after controlling for education, unemployment status, race, gender, age, marital status, and household children, waiting time associated with time spent traveling to use services, and work hours. We also show evidence suggesting that while work schedule autonomy likely plays a role in this gap, it does not fully explain it.

The differences become even more stark when focusing on two essential activities: obtaining medical care and shopping. On an average day when both a high- and low-income person wait for medical care, the poorer person waits an average of 18 minutes longer to receive that care. Among shoppers kept waiting for some amount of time, low-income people wait about 9 minutes longer.

Our analysis of differences in the likelihood of waiting by race reveal that low-income 
White and Black Americans are both more likely to wait when seeking services than their wealthier same-race peers, which suggests that for these groups, SES plays a more prominent role than race in whether or not a person can avoid waiting altogether. This is not the case for Latino(a) Americans, who are more likely to wait for services than White Americans in their same income bracket. Asian Americans are the least likely to wait for goods and services, regardless of income. However, when analyzing gaps in time spent waiting for services among people who wait at all, we find that while wealthier White, Asian, and Latino(a) people all face less waiting time than their low-income, same-race peers, wealthier Black people wait as long or longer than lower-income Black people and wealthy non-Black people.

Gender differences in waiting reveal that women are more likely to spend time on activities that involve waiting, but high-income women are as likely as men to avoid waiting for those goods and services, given any time spent on them. There is, however, one gender gap in the amount of time spent waiting: higher-income women wait significantly less than low-income women, low-income men, and higher-income men.

Our results underscore an inequity in how society values the time of people from the poorest households. The income-gap in waiting time we document reflects a difference between rich and poor Americans in autonomy, productive time left available each day, and daily quality of life. Moreover, the gap cannot be explained by transit, working time, education, or family circumstances, which points to the possibility that neighborhood quality differences leave poor Americans with less access to quality, efficient service in trying to meet their daily needs. The difference in treatment when seeking basic services represents a pernicious inequality in the daily lives of the rich and poor. Beyond the economic effects of imposed unproductive time, additional time waiting for basic services makes predictable daily schedules more difficult, leading to stress and creating spillovers into the quality of time spent in other activities (Roy et al., 2004). There are a number of policy and management responses — big and small — that might be considered to help mitigate this particular manifestation of inequality. 
First, building schedule flexibility into everyday, necessary institutions would increase access for poor and low-income families (Roy et al. 2004). For example, longer daycare hours and expanded, free afterschool programming would immediately increase low-income parents' discretionary time by allowing less congested drop-off and pick-up times and more accommodation for shift work that may not align with a typical, 9-to-5 work schedule. Similarly, medical clinics could adopt more flexible and predictable appointment scheduling aimed at both reducing wait times and accommodating a wider range of work schedules.

Second, reducing the administrative burden and time constraints of social safety net programs would reduce time inequality, as the poor are more burdened than others, and such burdens are time consuming (Herd and Moynihan, 2020). For example, the Housing Choice Voucher program requires recipients use their voucher within a specified amount of time, and these time limits often leave recipients feeling pressured in their housing search (DeLuca et al., 2013), increasing the costs of using the program and contributing to lower program uptake (Barnes, 2021). Policy changes spurred by the COVID-19 pandemic have actually made some progress in this area; for example, the Supplemental Nutrition Assistance Program (SNAP) online purchasing pilot program, which allows participants to use their SNAP benefits for online grocery ordering, was rapidly expanded and is now available in nearly every state. Other programs, such as the Women, Infants, and Children (WIC) program, should consider similar policy changes.

Third, relatedly, Medicaid could be reformed to increase the number of healthcare providers who accept Medicaid-covered patients. Currently, the combination of Medicaid providing lower reimbursement rates than private insurance and the lack of a mandate for providers to accept Medicaid makes doctors less likely to accept Medicaid than other types of insurance. As mentioned above, research shows that differences in wait times for medical care between higher and lower income people is largely driven by differences in the types of practices and providers that accept Medicaid, and is larger in states with lower Medicaid reimbursement rates (Oostrom et al., 2017). This suggests that Medicaid patients in higher reimbursement 
rate states have more access to high quality or less overburdened practices and providers, and offers a simple and direct way to reduce the income-gap in waiting for medical services we document in our analysis.

Fourth, labor and employment policy changes might be another avenue to reduce the SES gap in waiting time through two primary avenues. First, policy changes that provide more autonomy and predictability in work schedules for low-income and hourly workers could help provide needed flexibility to optimize service appointments, creating smoother demand for services throughout the day for providers and reducing wait times for low-income households. Fair workweek laws, which provide workers with the right to advanced notice of their work schedule, compensation for schedule changes, and the right to request scheduling accommodations, have recently been enacted in five major cities and the state of Oregon in an attempt to reduce the propensity for hourly work to be "on-call" and unpredictable week-to-week (Wolfe et al., 2018). Expanding such laws can provide low-income workers the work schedule flexibility available to high-income workers, and preliminary evidence suggests employers may also benefit from increased productivity (Kesavan et al., 2021). Second, policies that reduce poverty and economic inequality will likely reduce time inequality as well. Simply increasing household income, through policies such as refundable child tax credits, the Earned Income Tax Credit, and minimum wage laws, may reduce the time burden of poverty, leaving more productive time available for contributing to society and personal well-being.

Finally, more equitable investment in neighborhoods, especially neighborhoods of color, and public transit can help reduce the SES gap in time spent waiting for services. To the extent that waiting times reflect inefficient or low-quality service, increasing the number of options in a small geographic space can induce service improvements and provide additional options for surplus demand. As noted previously, low-income people and people of color often face limited options for both retail and financial services (Dutko et al., 2012; CookseyStowers et al., 2017; Schuetz et al. 2012; Dunham, 2018). Facing such thin competition in 
low-income neighborhoods, businesses may both understaff to reduce costs and face excess demand - a combination that likely feeds long wait times. The relative lack of options for services forces low-income people to choose between spending more time traveling to higher quality services elsewhere or spending more time waiting for service locally. Reducing neighborhood segregation by race and class and investing more heavily in basic services in communities of color could help provide the competition necessary to both improve service and reduce excess demand for services.

Our work also suggests directions for future research. First, future work should continue to investigate the behavioral changes that are likely differentially induced by these wait disparities. Such work could help reveal how time and waiting inequality work as mechanisms for other observed inequalities, such as health outcomes. Future work examining how exogenous exposure to waiting in grocery stores changes purchasing patterns or whether exposure to waiting in medical clinics alters how long patients delay scheduling an appointment would help illuminate some of the most important potential consequences of the waiting gap we document in our analysis.

Second, while valuable, the ATUS has several limitations that likely bias our estimates downward. In other words, we are likely underestimating the true time gaps in time spent waiting for services. Further, because the ATUS captures respondents' time on one particular day, it is not well-suited to measure differences in time spent waiting for less common but important activities, such as applying for social safety net benefits or voting. Future work should use other data sources or collect data on time use and waiting time for specific activities. Relatedly, the ATUS comes from the United States; however, several countries (e.g., Germany, the United Kingdom, Australia, Japan, Korea, Canada, New Zealand, and South Africa) collect time diary data from representative samples. International comparisons of the SES gap in waiting time could provide valuable insights regarding the societal, economic, and cultural differences that shape waiting time.

Third, while our analyses shed some light on some potential mechanisms underlying these 
differences - such as work schedules - it must be paired with existing and future qualitative work to more fully understand these experiences. For example, in an ethnographic study of low-income mothers in Chicago, Roy et al. (2004) emphasize the lack of control over their time these mothers reported. As the authors note, "If low-income working mothers could not make the health department's office hours for their children's immunization, they could not opt to use private physicians. They also could not choose to use flex-time options on their jobs to stay home to nurse sick children. Instead, these mothers risked lost wages, valuable work hours, and even job security by giving priority to inevitable family crises." The authors also describe the extra hours these mothers built into their daily commutes to accommodate public transit wait times. Such qualitative insights can help researchers and policy-makers identify the particular levers throughout which low-income people's time can be better respected in daily life.

Finally, this work might inspire research questions in a number of social science fields. For example, public administration scholars might analyze whether socioeconomic or racial representation among public sector employees reduces wait times. Political Scientists might consider the effects of time spent waiting on public opinion of government and subsequent voting and civic participation behaviors. Economists might consider the productivity costs and relative economic value of time suggested by our estimated wait time gap and the influence of market competition on wait times. In short, the descriptive inequities in wait times we observe here reflect a broad array of social, political, and economic forces that warrant continued study. 


\section{References}

Allard, M. D. (2018). What is the impact of recoding travel activities in the american time use survey? Monthly Labor Review, pages 1-13.

Auyero, J. (2011). Patients of the state: An ethnographic account of poor people's waiting. Latin American Research Review, pages 5-29.

Baker, C., Floros, T., and Kristensen, K. (2020). Vehicle financing inequality: What can be done? Technical report, Federal Reserve Bank of St. Louis.

Barnes, C. Y. (2021). "it takes a while to get used to": The costs of redeeming public benefits. Journal of Public Administration Research and Theory, 31(2):295-310.

Bauer, L., Buckner, E., Estep, S., Moss, E., and Welch, M. (2021). Ten economic facts on how mothers spend their time. Technical report, Brookings Institute.

Bittman, M. (2002). Social participation and family welfare: The money and time costs of leisure in australia. Social Policy \&f Administration, 36(4):408-425.

Bittman, M. and Wajcman, J. (2000). The rush hour: The character of leisure time and gender equity. Social Forces, 79(1):165-189.

Bleustein, C., Rothschild, D. B., Valen, A., Valatis, E., Schweitzer, L., and Jones, R. (2014). Wait times, patient satisfaction scores, and the perception of care. The American Journal of Managed Care, 20(5):393-400.

Chen, M. K., Haggag, K., Pope, D. G., and Rohla, R. (2019). Racial disparities in voting wait times: evidence from smartphone data. Review of Economics and Statistics, pages $1-27$.

Chetty, R. and Hendren, N. (2018). The impacts of neighborhoods on intergenerational mobility i: Childhood exposure effects. The Quarterly Journal of Economics, 133(3):11071162.

Chetty, R., Hendren, N., and Katz, L. F. (2016). The effects of exposure to better neighborhoods on children: New evidence from the moving to opportunity experiment. American Economic Review, 106(4):855-902.

Cohen, E. F. (2018). The political value of time: Citizenship, duration, and democratic justice. Cambridge University Press.

Cohen, P. N. (1998). Replacing housework in the service economy: Gender, class, and race-ethnicity in service spending. Gender $\&$ Society, 12(2):219-231.

Cooksey-Stowers, K., Schwartz, M. B., and Brownell, K. D. (2017). Food swamps predict obesity rates better than food deserts in the united states. International journal of environmental research and public health, 14(11):1366.

DeLuca, S., Garboden, P. M., and Rosenblatt, P. (2013). Segregating shelter: How housing policies shape the residential locations of low-income minority families. The ANNALS of the American Academy of Political and Social Science, 647(1):268-299.

Douthitt, R. A. (2000). "time to do the chores?" factoring home-production needs into measures of poverty. Journal of Family and Economic Issues, 21(1):7-22.

Dunham, I. M. (2018). Forgotten landscapes of financial exclusion: A geographic analysis of banking deserts and the two-tiered financial service system. In Proceedings of the International Association for Business and Society, volume 29, pages 96-109.

Dutko, P., Ver Ploeg, M., and Farrigan, T. (2012). Characteristics and influential factors of food deserts. Technical report. 
Engel, R. S. and Calnon, J. M. (2004). Examining the influence of drivers' characteristics during traffic stops with police: Results from a national survey. Justice Quarterly, 21(1):49-90.

Gee, G. C., Hing, A., Mohammed, S., Tabor, D. C., and Williams, D. R. (2019). Racism and the life course: Taking time seriously. American Journal of Public Health, 109(S1):S43S47.

Harvey, A. S. and Mukhopadhyay, A. K. (2007). When twenty-four hours is not enough: Time poverty of working parents. Social Indicators Research, 82(1):57-77.

Hegerty, S. W. (2016). Commercial bank locations and "banking deserts": A statistical analysis of milwaukee and buffalo. The Annals of Regional Science, 56(1):253-271.

Herd, P. and Moynihan, D. (2020). Administrative burdens in health policy. Journal of Health $\&$ Human Services Administration, 43(1).

Herd, P. and Moynihan, D. P. (2019). Administrative burden: Policymaking by other means. Russell Sage Foundation.

Hochschild, A. and Machung, A. (2012). The second shift: Working families and the revolution at home. Penguin.

Hsiang, W. R., Lukasiewicz, A., Gentry, M., Kim, C.-Y., Leslie, M. P., Pelker, R., Forman, H. P., and Wiznia, D. H. (2019). Medicaid patients have greater difficulty scheduling health care appointments compared with private insurance patients: a metaanalysis. INQUIRY: The Journal of Health Care Organization, Provision, and Financing, 56:0046958019838118.

Jabs, J. and Devine, C. M. (2006). Time scarcity and food choices: an overview. Appetite, 47(2):196-204.

Juster, F. T. and Stafford, F. P. (1991). The allocation of time: Empirical findings, behavioral models, and problems of measurement. Journal of Economic literature, 29(2):471-522.

Kalenkoski, C. M., Hamrick, K. S., and Andrews, M. (2011). Time poverty thresholds and rates for the us population. Social Indicators Research, 104(1):129-155.

Kendig, S. M. and Bianchi, S. M. (2008). Single, cohabitating, and married mothers' time with children. Journal of Marriage and Family, 70(5):1228-1240.

Kesavan, S., Lambert, S., Williams, J., and Pendem, P. (2021). Doing well by doing good: Improving store performance with employee-friendly scheduling practices at the gap, inc. SSRN Working Paper.

Kiel, P. and Eisinger, J. Who's more likely to be audited: A person making 20, 000|or400,000? ProPublica.

Kimbrough, G. (2019). Measuring commuting in the american time use survey. Journal of Economic and Social Measurement, 44(1):1-17.

Kossek, E. E. and Lautsch, B. A. (2018). Work-life flexibility for whom? occupational status and work-life inequality in upper, middle, and lower level jobs. Academy of Management Annals, 12(1):5-36.

Kugelmass, H. (2016). "sorry, i'm not accepting new patients" an audit study of access to mental health care. Journal of Health and Social Behavior, 57(2):168-183.

Liederbach, E., Sisco, M., Wang, C., Pesce, C., Sharpe, S., Winchester, D. J., and Yao, K. (2015). Wait times for breast surgical operations, 2003-2011: a report from the national cancer data base. Annals of surgical oncology, 22(3):899-907.

Loprest, P., Acs, G., Ratcliffe, C., and Vinopal, K. (2009). Who are low-wage workers? 
Technical report, U.S. Department of Health and Human Services, Office of the Assistant Secretary for Planning and Evaluation.

Massey, D. S. and Lundy, G. (2001). Use of black english and racial discrimination in urban housing markets: New methods and findings. Urban affairs review, 36(4):452-469.

Mattingly, M. J. and Blanchi, S. M. (2003). Gender differences in the quantity and quality of free time: The us experience. Social Forces, 81(3):999-1030.

Oostrom, T., Einav, L., and Finkelstein, A. (2017). Outpatient office wait times and quality of care for medicaid patients. Health Affairs, 36(5):826-832.

Pendall, R., Hayes, C., George, A. T., McDade, Z., Dawkins, C., Jeon, J. S., Knaap, E., Blumenberg, E., Pierce, G., and Smart, M. (2014). Driving to opportunity: Understanding the links among transportation access, residential outcomes, and economic opportunity for housing voucher recipients.

Pettigrew, S. (2017). The racial gap in wait times: why minority precincts are underserved by local election officials. Political Science Quarterly, 132(3):527-547.

Pierson, E., Simoiu, C., Overgoor, J., Corbett-Davies, S., Jenson, D., Shoemaker, A., Ramachandran, V., Barghouty, P., Phillips, C., Shroff, R., et al. (2020). A large-scale analysis of racial disparities in police stops across the united states. Nature Human Behaviour, $4(7): 736-745$.

Quinton, S. (2014). How car ownership helps the working poor get ahead. The Atlantic.

Ray, V., Herd, P., and Moynihan, D. (2020). Racialized burdens: Applying racialized organization theory to the administrative state.

Roy, K. M., Tubbs, C. Y., and Burton, L. M. (2004). Don't have no time: Daily rhythms and the organization of time for low-income families. Family Relations, 53(2):168-178.

Sayer, L. C. (2005). Gender, time and inequality: Trends in women's and men's paid work, unpaid work and free time. Social Forces, 84(1):285-303.

Schuetz, J., Kolko, J., and Meltzer, R. (2012). Are poor neighborhoods "retail deserts"? Regional Science and Urban Economics, 42(1-2):269-285.

Schwartz, B. (1974). Waiting, exchange, and power: The distribution of time in social systems. American Journal of Sociology, 79(4):841-870.

Stewart, J. (2013). Tobit or not tobit? Journal of Economic and Social Measurement, $38(3): 263-290$.

Strazdins, L., Griffin, A. L., Broom, D. H., Banwell, C., Korda, R., Dixon, J., Paolucci, F., and Glover, J. (2011). Time scarcity: another health inequality? Environment and Planning A, 43(3):545-559.

Sturman, M. C. (1999). Multiple approaches to analyzing count data in studies of individual differences: The propensity for type i errors, illustrated with the case of absenteeism prediction. Educational and Psychological Measurement, 59(3):414-430.

Turner, J. and Grieco, M. (2000). Gender and time poverty: the neglected social policy implications of gendered time, transport and travel. Time \& Society, 9(1):129-136.

Venn, D. and Strazdins, L. (2017). Your money or your time? how both types of scarcity matter to physical activity and healthy eating. Social Science \& Medicine, 172:98-106.

Vickery, C. (1977). The time-poor: A new look at poverty. Journal of Human Resources, pages $27-48$.

Wakefield, S. and Uggen, C. (2010). Incarceration and stratification. Annual review of sociology, 36:387-406. 
Warren, T. (2003). Class and gender-based working time? time poverty and the division of domestic labour. Sociology, 37(4):733-752.

Western, B. and Pettit, B. (2010). Incarceration \& social inequality. Daedalus, 139(3):8-19.

Williams, J. R., Masuda, Y. J., and Tallis, H. (2016). A measure whose time has come: Formalizing time poverty. Social Indicators Research, 128(1):265-283.

Wolfe, J., Jones, J., and Cooper, D. (2018). 'fair workweek' laws help more than 1.8 million workers. Technical report, Economic Policy Institute.

Zilanawala, A. (2016). Women's time poverty and family structure: Differences by parenthood and employment. Journal of Family Issues, 37(3):369-392. 


\section{Tables}

Table 1: Summary of analytic sample, 2003-2019

\begin{tabular}{|c|c|c|c|c|c|c|c|}
\hline & \multirow[t]{2}{*}{ (1) } & \multirow{2}{*}{$\begin{array}{l}(2) \\
\text { All } \\
\end{array}$} & \multirow[t]{2}{*}{ (3) } & \multirow{2}{*}{\multicolumn{2}{|c|}{$\begin{array}{l}(4) \\
\text { Any Time }\end{array}$}} & \multirow{2}{*}{\multicolumn{2}{|c|}{$\begin{array}{l}(6) \\
\text { Non-Zero }\end{array}$}} \\
\hline & & & & & & & \\
\hline & All & Low & High & Low & High & Low & High \\
\hline \multirow[t]{2}{*}{ Waiting for services ( $\mathrm{T}$ in mins.) } & 1.88 & $2.24^{* * *}$ & 1.24 & $3.70^{* * *}$ & 1.80 & $44.69^{* * *}$ & 28.89 \\
\hline & $(15.47)$ & $(16.87)$ & $(10.02)$ & $(19.47)$ & $(10.34)$ & $(61.62)$ & $(39.36)$ \\
\hline \multirow[t]{2}{*}{ Waiting for services $(\mathrm{T} \mid \mathrm{T}>0)$} & 39.96 & $44.69 * * *$ & 28.89 & $41.59 * * *$ & 26.75 & $44.69 * * *$ & 28.89 \\
\hline & $(59.62)$ & $(61.62)$ & $(39.36)$ & $(51.83)$ & $(30.35)$ & $(61.62)$ & $(39.36)$ \\
\hline \multirow[t]{2}{*}{ Travel time for services } & 27.15 & $25.69 * * *$ & 30.21 & $47.61^{*}$ & 49.20 & $72.29 * *$ & 64.76 \\
\hline & $(44.88)$ & $(44.68)$ & $(47.48)$ & $(51.70)$ & $(53.72)$ & $(65.77)$ & $(51.63)$ \\
\hline $\mathrm{HH}$ income $\$ 20 \mathrm{~K}$ or less & 0.20 & 1.00 & 0.00 & 1.00 & 0.00 & 1.00 & 0.00 \\
\hline HH income $\$ 150 \mathrm{~K}$ or more & 0.08 & 0.00 & 1.00 & 0.00 & 1.00 & 0.00 & 1.00 \\
\hline White & 0.82 & $0.75^{* * *}$ & 0.85 & $0.75^{* * *}$ & 0.85 & $0.72^{* * *}$ & 0.87 \\
\hline Black & 0.12 & $0.20 * * *$ & 0.05 & $0.19 * * *$ & 0.05 & $0.22^{* * *}$ & 0.05 \\
\hline Asian & 0.04 & $0.03^{* * *}$ & 0.08 & $0.03^{* * *}$ & 0.08 & $0.01^{* * *}$ & 0.07 \\
\hline Latino(a) & 0.15 & $0.18^{* * *}$ & 0.07 & $0.19^{* * *}$ & 0.07 & $0.20 * * *$ & 0.12 \\
\hline \multirow[t]{2}{*}{ Age } & 44.87 & $47.14^{* * *}$ & 43.07 & $44.71^{* * *}$ & 41.99 & $47.13^{* * *}$ & 41.50 \\
\hline & $(18.52)$ & $(20.46)$ & $(16.15)$ & $(20.33)$ & $(16.35)$ & $(21.36)$ & $(18.53)$ \\
\hline Male & 0.48 & $0.44^{* * *}$ & 0.50 & $0.41^{* * *}$ & 0.45 & 0.37 & 0.40 \\
\hline$<$ HS diploma & 0.17 & $0.29 * * *$ & 0.10 & $0.26^{* * *}$ & 0.13 & $0.29 * * *$ & 0.20 \\
\hline College degree + & 0.29 & $0.13^{* * *}$ & 0.63 & $0.14^{* * *}$ & 0.62 & $0.12^{* * *}$ & 0.54 \\
\hline $\mathrm{R}$ is married & 0.53 & $0.35^{* * *}$ & 0.68 & $0.35^{* * *}$ & 0.66 & $0.33^{* * *}$ & 0.60 \\
\hline \multirow[t]{2}{*}{ Num. of HH children } & 0.78 & $0.71^{* * *}$ & 0.88 & $0.82^{* * *}$ & 0.97 & $0.74^{* * *}$ & 0.95 \\
\hline & $(1.15)$ & $(1.18)$ & $(1.12)$ & $(1.24)$ & $(1.16)$ & $(1.20)$ & $(1.15)$ \\
\hline Lives in MSA & 0.83 & $0.78^{* * *}$ & 0.94 & $0.79^{* * *}$ & 0.94 & $0.79 * * *$ & 0.95 \\
\hline Observations & 210,586 & 49,688 & 14,852 & 22,721 & 8,410 & 2,078 & 538 \\
\hline
\end{tabular}

Note: Standard deviations in parentheses; the statistical significance of mean differences between high- and low-income respondents is tested using t-tests. ${ }^{*} \mathrm{p}<.10,{ }^{* *} \mathrm{p}<.05,{ }^{* * *} \mathrm{p}<.01$. Weighted using BLS provided sampling weights. Low $=\$ 20 \mathrm{~K}$ or less household income. High $=\$ 150 \mathrm{~K}$ or more household income. $\mathrm{HH}=$ household. $\mathrm{HS}=$ High school 
Table 2: LPM estimates of SES gap in likelihood of no waiting, weighted

\begin{tabular}{lccccccc}
\hline \hline & $(1)$ & $(2)$ & $(3)$ & $(4)$ & $(5)$ & $(6)$ & $(7)$ \\
\hline HH income $\$ 150 \mathrm{~K}$ or more & (Omitted) & & & & & & \\
HH income $\$ 20 \mathrm{~K}$ or less & $-0.03^{* * *}$ & $-0.03^{* * *}$ & $-0.03^{* * *}$ & $-0.02^{* * *}$ & $-0.02^{* * *}$ & $-0.01^{* * *}$ & $-0.01^{* *}$ \\
& $(0.00)$ & $(0.00)$ & $(0.00)$ & $(0.00)$ & $(0.00)$ & $(0.00)$ & $(0.00)$ \\
HH income $\$ 20 \mathrm{~K}$ to $\$ 40 \mathrm{~K}$ & $-0.02^{* * *}$ & $-0.02^{* * *}$ & $-0.02^{* * *}$ & $-0.02^{* * *}$ & $-0.01^{* * *}$ & $-0.01^{* *}$ & -0.00 \\
& $(0.00)$ & $(0.00)$ & $(0.00)$ & $(0.00)$ & $(0.00)$ & $(0.00)$ & $(0.00)$ \\
& $-0.01^{* * *}$ & $-0.01^{* * *}$ & $-0.01^{* * *}$ & $-0.01^{* * *}$ & $-0.01^{* *}$ & $-0.01^{*}$ & -0.00 \\
HH income $\$ 40 \mathrm{~K}$ to $\$ 60 \mathrm{~K}$ & $(0.00)$ & $(0.00)$ & $(0.00)$ & $(0.00)$ & $(0.00)$ & $(0.00)$ & $(0.00)$ \\
& $-0.01^{*}$ & $-0.01^{* *}$ & $-0.01^{* *}$ & $-0.01^{* *}$ & $-0.01^{* *}$ & -0.01 & -0.00 \\
& $(0.01)$ & $(0.01)$ & $(0.01)$ & $(0.01)$ & $(0.01)$ & $(0.01)$ & $(0.00)$ \\
HH income $\$ 60 \mathrm{~K}$ to $\$ 75 \mathrm{~K}$ & $-0.01^{*}$ & $-0.01^{*}$ & $-0.01^{* *}$ & $-0.01^{* *}$ & $-0.01^{* *}$ & $-0.01^{* *}$ & -0.00 \\
& $(0.00)$ & $(0.00)$ & $(0.00)$ & $(0.00)$ & $(0.00)$ & $(0.00)$ & $(0.00)$ \\
HH income $\$ 75 \mathrm{~K}$ to $\$ 100 \mathrm{~K}$ & $-0.01^{*}$ & $-0.01^{*}$ & $-0.01^{*}$ & $-0.01^{* *}$ & $-0.01^{*}$ & $-0.01^{*}$ & -0.00 \\
& $(0.00)$ & $(0.00)$ & $(0.00)$ & $(0.00)$ & $(0.00)$ & $(0.00)$ & $(0.00)$ \\
HH income $\$ 100 \mathrm{~K}$ to $\$ 150 \mathrm{~K}$ & $\checkmark$ & $\checkmark$ & $\checkmark$ & $\checkmark$ & $\checkmark$ & $\checkmark$ & $\checkmark$ \\
& & $\checkmark$ & $\checkmark$ & $\checkmark$ & $\checkmark$ & $\checkmark$ & $\checkmark$ \\
Controls for time trends & & & $\checkmark$ & $\checkmark$ & $\checkmark$ & $\checkmark$ & $\checkmark$ \\
Controls for MSA & & & & $\checkmark$ & $\checkmark$ & $\checkmark$ & $\checkmark$ \\
Controls for travel time & & & & & $\checkmark$ & $\checkmark$ & $\checkmark$ \\
Controls for work time & & & & & & $\checkmark$ & $\checkmark$ \\
Controls for family & & & & & & & $\checkmark$ \\
Controls for demos. \& education & & & & & & $\checkmark$ \\
Controls for state FE & 107,749 & 107,749 & 107,749 & 107,749 & 107,749 & 107,749 & 107,749 \\
\hline Adjusted $R^{2}$ & & & & & $\checkmark$ & \\
Observations & & & & & & & $\checkmark$ \\
\hline
\end{tabular}

Note: Robust standard errors clustered at the state-level (in parentheses); ${ }^{*} \mathrm{p}<.10,{ }^{* *} \mathrm{p}<.05,{ }^{* * *} \mathrm{p}<.01$. 
Table 3: OLS estimates of SES gap in waiting time (in minutes; $\mathrm{T} \mid \mathrm{T}>0$ ), weighted

\begin{tabular}{lccccccc}
\hline \hline & $(1)$ & $(2)$ & $(3)$ & $(4)$ & $(5)$ & $(6)$ & $(7)$ \\
\hline HH income $\$ 150 \mathrm{~K}$ or more & (Omitted) & & & & & & \\
HH income $\$ 20 \mathrm{~K}$ or less & $12.11^{* * *}$ & $11.54^{* * *}$ & $11.26^{* * *}$ & $8.59^{* * *}$ & $10.80^{* * *}$ & $7.34^{* *}$ & $5.83^{* * *}$ \\
& $(2.76)$ & $(2.83)$ & $(2.84)$ & $(2.68)$ & $(2.65)$ & $(2.76)$ & $(2.16)$ \\
HH income $\$ 20 \mathrm{~K}$ to $\$ 40 \mathrm{~K}$ & $12.21^{* * *}$ & $11.64^{* * *}$ & $11.62^{* * *}$ & $9.49^{* * *}$ & $10.24^{* * *}$ & $7.26^{* * *}$ & $3.92^{*}$ \\
& $(3.00)$ & $(2.99)$ & $(2.94)$ & $(2.78)$ & $(2.82)$ & $(2.68)$ & $(2.26)$ \\
& $10.12^{* * *}$ & $9.74^{* * *}$ & $9.64^{* * *}$ & $8.56^{* * *}$ & $8.73^{* * *}$ & $6.82^{* *}$ & 3.64 \\
HH income $\$ 40 \mathrm{~K}$ to $\$ 60 \mathrm{~K}$ & $(2.64)$ & $(2.64)$ & $(2.62)$ & $(2.70)$ & $(2.62)$ & $(2.67)$ & $(2.20)$ \\
& $6.21^{*}$ & $5.80^{*}$ & $5.70^{*}$ & 4.95 & 4.87 & 3.31 & 2.15 \\
HH income $\$ 60 \mathrm{~K}$ to $\$ 75 \mathrm{~K}$ & $(3.27)$ & $(3.31)$ & $(3.26)$ & $(3.29)$ & $(3.29)$ & $(3.25)$ & $(2.54)$ \\
& $6.76^{*}$ & $6.53^{*}$ & $6.53^{*}$ & 6.23 & 5.66 & 4.82 & 3.83 \\
HH income $\$ 75 \mathrm{~K}$ to $\$ 100 \mathrm{~K}$ & $(3.87)$ & $(3.88)$ & $(3.85)$ & $(3.80)$ & $(3.77)$ & $(3.83)$ & $(2.71)$ \\
& 4.66 & 4.51 & 4.50 & 3.71 & 3.19 & 2.75 & 0.23 \\
HH income $\$ 100 \mathrm{~K}$ to $\$ 150 \mathrm{~K}$ & $(3.13)$ & $(3.14)$ & $(3.09)$ & $(2.91)$ & $(3.00)$ & $(2.98)$ & $(2.10)$ \\
\hline Controls for time trends & $\checkmark$ & $\checkmark$ & $\checkmark$ & $\checkmark$ & $\checkmark$ & $\checkmark$ & $\checkmark$ \\
Controls for MSA & & $\checkmark$ & $\checkmark$ & $\checkmark$ & $\checkmark$ & $\checkmark$ & $\checkmark$ \\
Controls for travel time & & & $\checkmark$ & $\checkmark$ & $\checkmark$ & $\checkmark$ & $\checkmark$ \\
Controls for work time & & & & $\checkmark$ & $\checkmark$ & $\checkmark$ & $\checkmark$ \\
Controls for family & & & & & $\checkmark$ & $\checkmark$ & $\checkmark$ \\
Controls for demos. \& education & & & & & & $\checkmark$ & $\checkmark$ \\
Controls for state FE & & & & & & & $\checkmark$ \\
\hline Adjusted $R^{2}$ & 0.01 & 0.01 & 0.02 & 0.03 & 0.03 & 0.04 & 0.03 \\
Observations & 8,363 & 8,363 & 8,363 & 8,363 & 8,363 & 8,363 & 8,363 \\
\hline \hline
\end{tabular}

Note: Robust standard errors clustered at the state-level (in parentheses); ${ }^{*} \mathrm{p}<.10,{ }^{* *} \mathrm{p}<.05,{ }^{* * *} \mathrm{p}<.01$. 


\section{Figures}

Figure 1: Time Spent Waiting for Medical Services for Self or HH Child (in minutes; T | T $>0$; weighted)

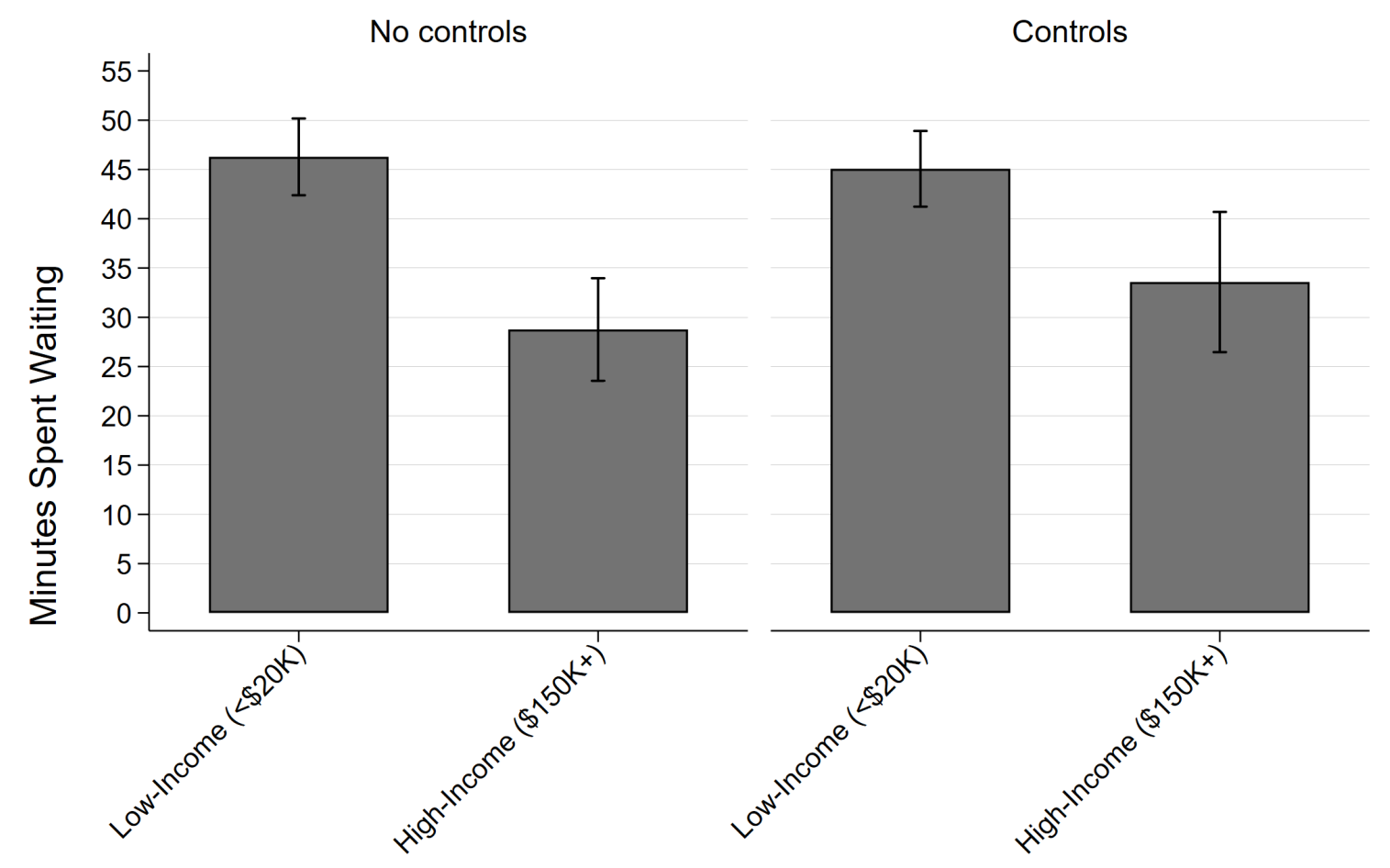

Note: Marginal effects from OLS regressions shown. No controls includes only controls for day of week, month, and year time trends. Controls accounts for travel and work time, being in an MSA, being unemployed, and family controls. Weighted using BLS provided weights. $\mathrm{HH}=$ household. $\mathrm{N}=832$. 
Figure 2: Time Spent Waiting While Shopping (in minutes; $\mathrm{T} \mid \mathrm{T}>0$; weighted)

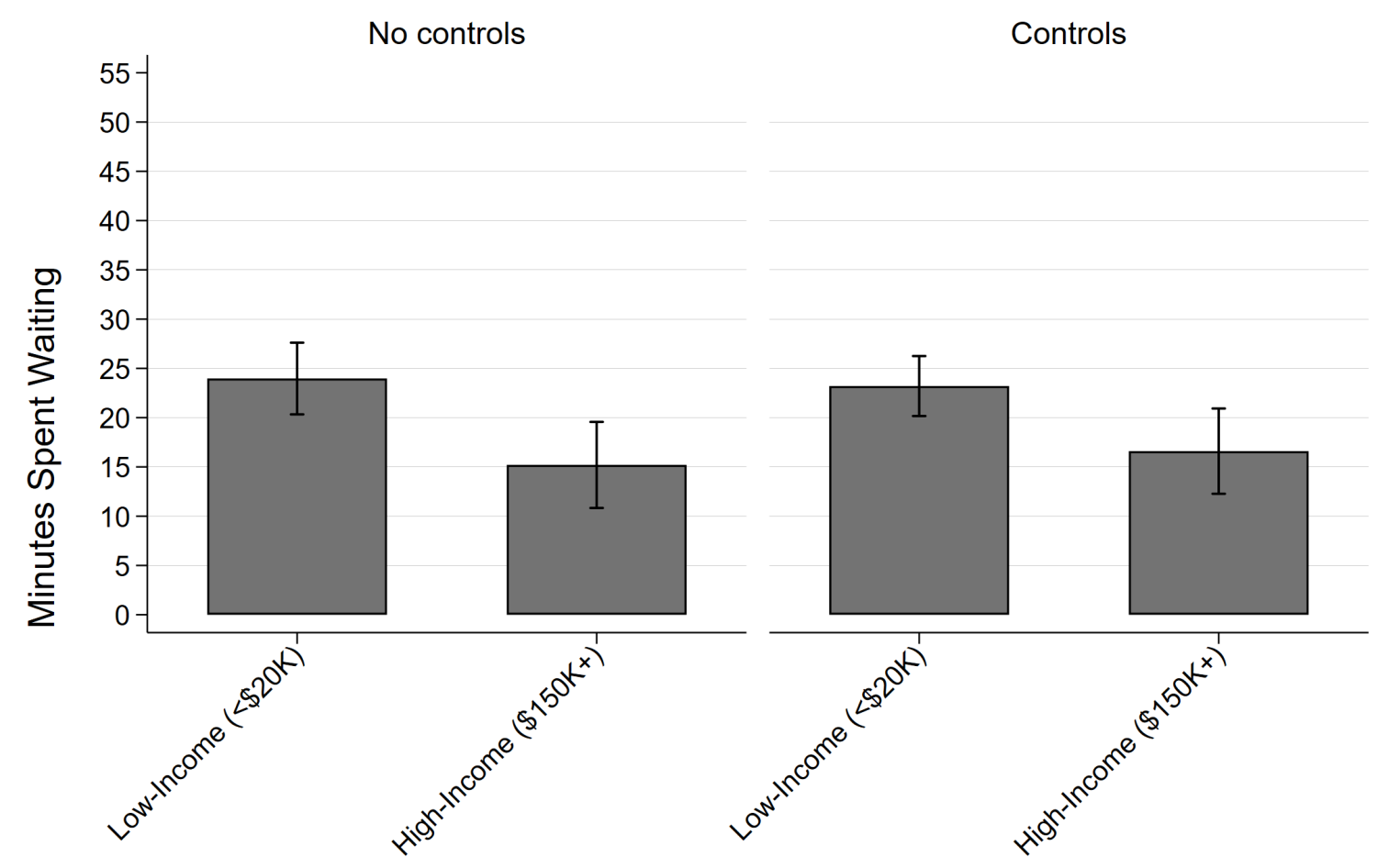

Note: Marginal effects from OLS regressions shown. No controls includes only controls for day of week, month, and year time trends. Controls accounts for travel and work time, being in an MSA, being unemployed, and family controls. Weighted using BLS provided weights. $\mathrm{N}=274$. 
Figure 3: Probability of Using Services by Gender, With Controls (weighted)

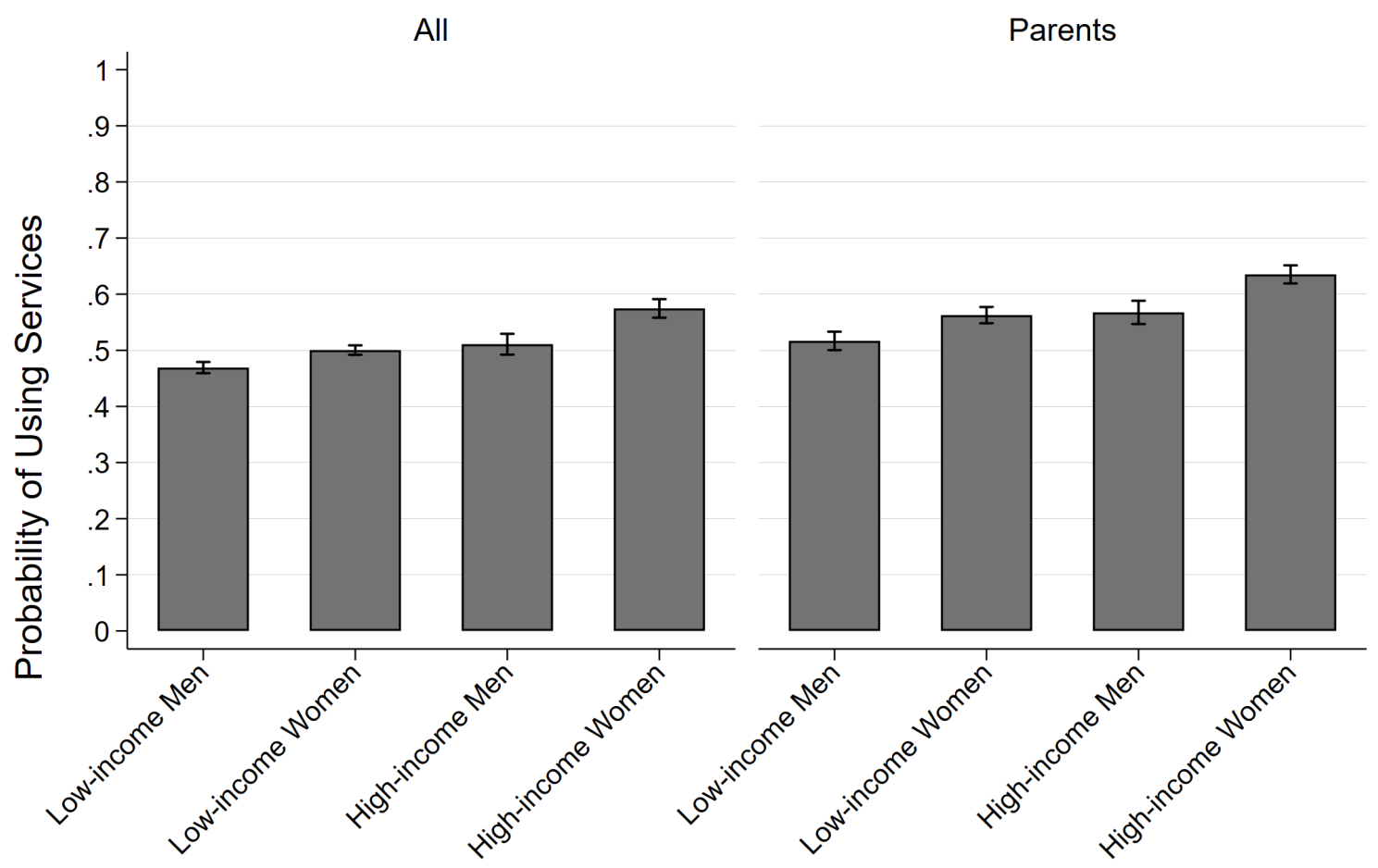

Note: Marginal effects from OLS regressions shown. Includes controls for day of week, month, and year time trends, travel and work time, whether respondent lives in an MSA, and unemployment status. Includes all observations, including those with zero waiting time. Parents includes only respondents with at least one household child 17 years old or younger. Weighted using BLS provided weights. $\mathrm{N}=64,540$ for All sample and $\mathrm{N}=26,585$ for Parents. 
Figure 4: Probability of Any Waiting for Services by Gender, With Controls (weighted)

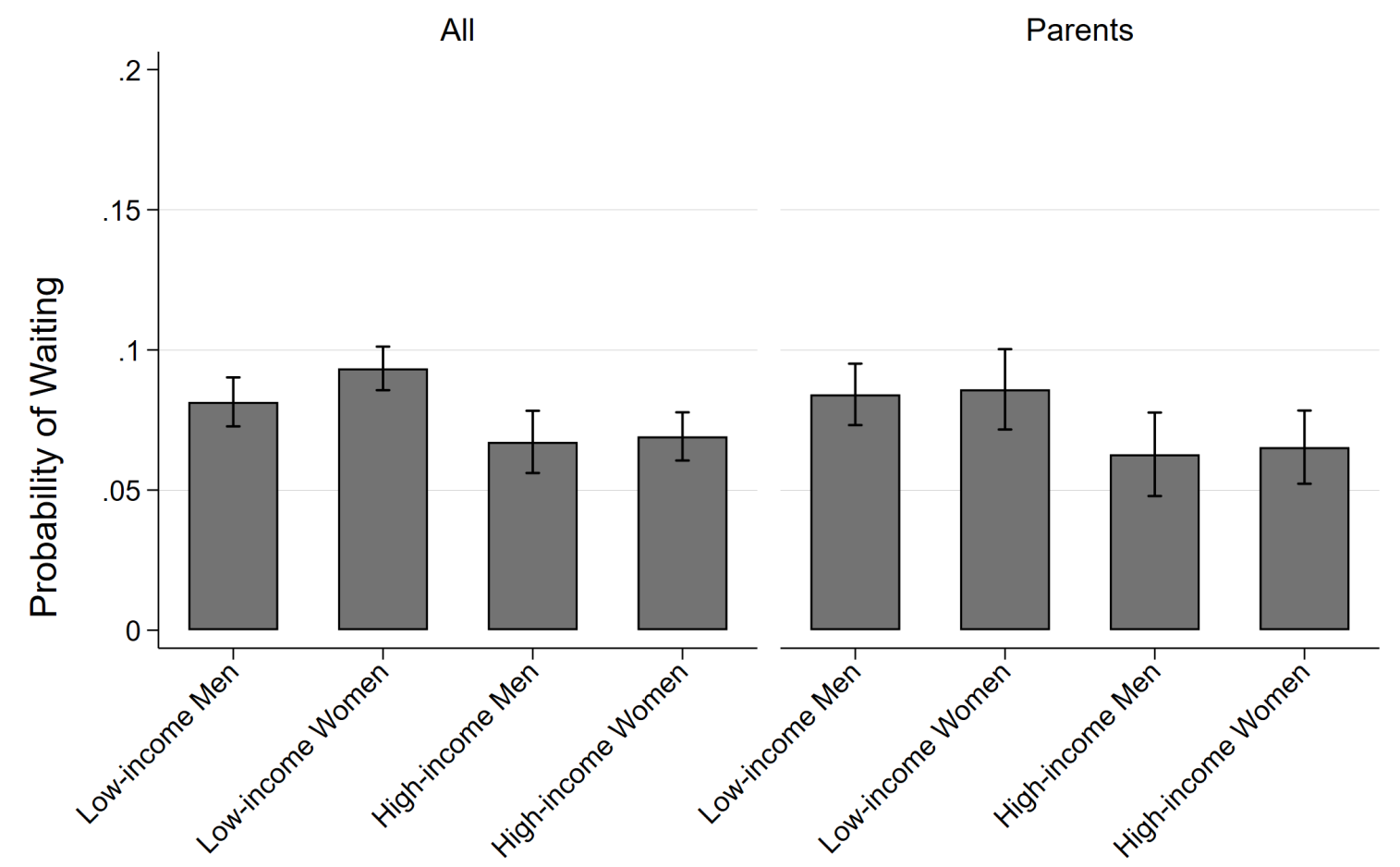

Note: Marginal effects from OLS regressions shown. Includes controls for day of week, month, and year time trends, travel and work time, whether respondent lives in an MSA, and unemployment status. Includes all observations, including those with zero waiting time. Parents includes only respondents with at least one household child 17 years old or younger. Weighted using BLS provided weights. N=31,131 for All sample and N=14,748 for Parents. 
Figure 5: Time Spent Waiting for Services by Gender, With Controls (in minutes; $\mathrm{T} \mid \mathrm{T}>$ 0 ; weighted)

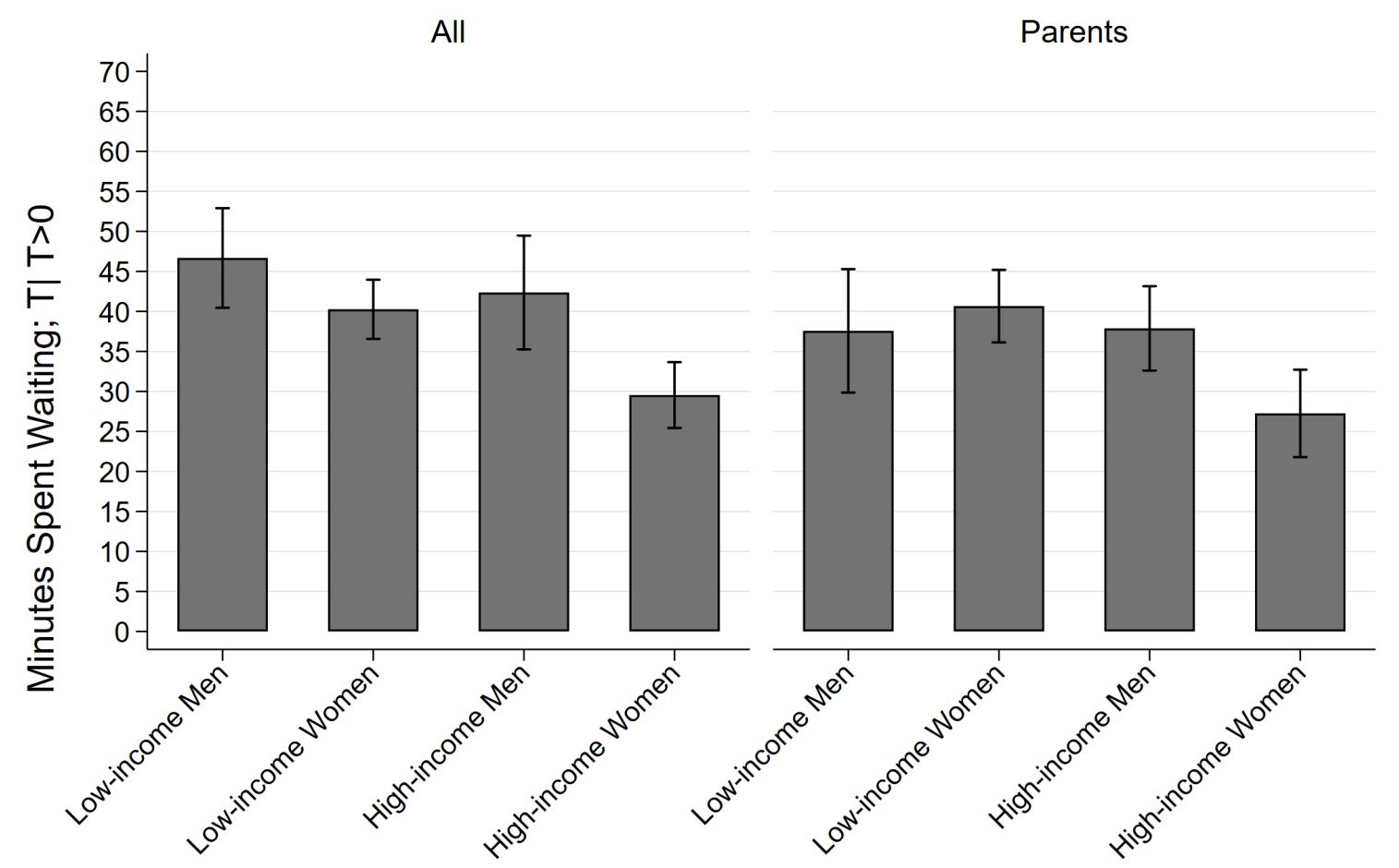

Note: Marginal effects from OLS regressions shown. Includes controls for day of week, month, and year time trends, travel and work time, whether respondent lives in an MSA, and unemployment status. Includes all observations, including those with zero waiting time. Parents includes only respondents with at least one household child 17 years old or younger. Weighted using BLS provided weights. $\mathrm{N}=2,616$ for full sample and $\mathrm{N}=1,075$ for parents. 
Figure 6: Probability of Any Waiting for Services by Race, With Controls (weighted)

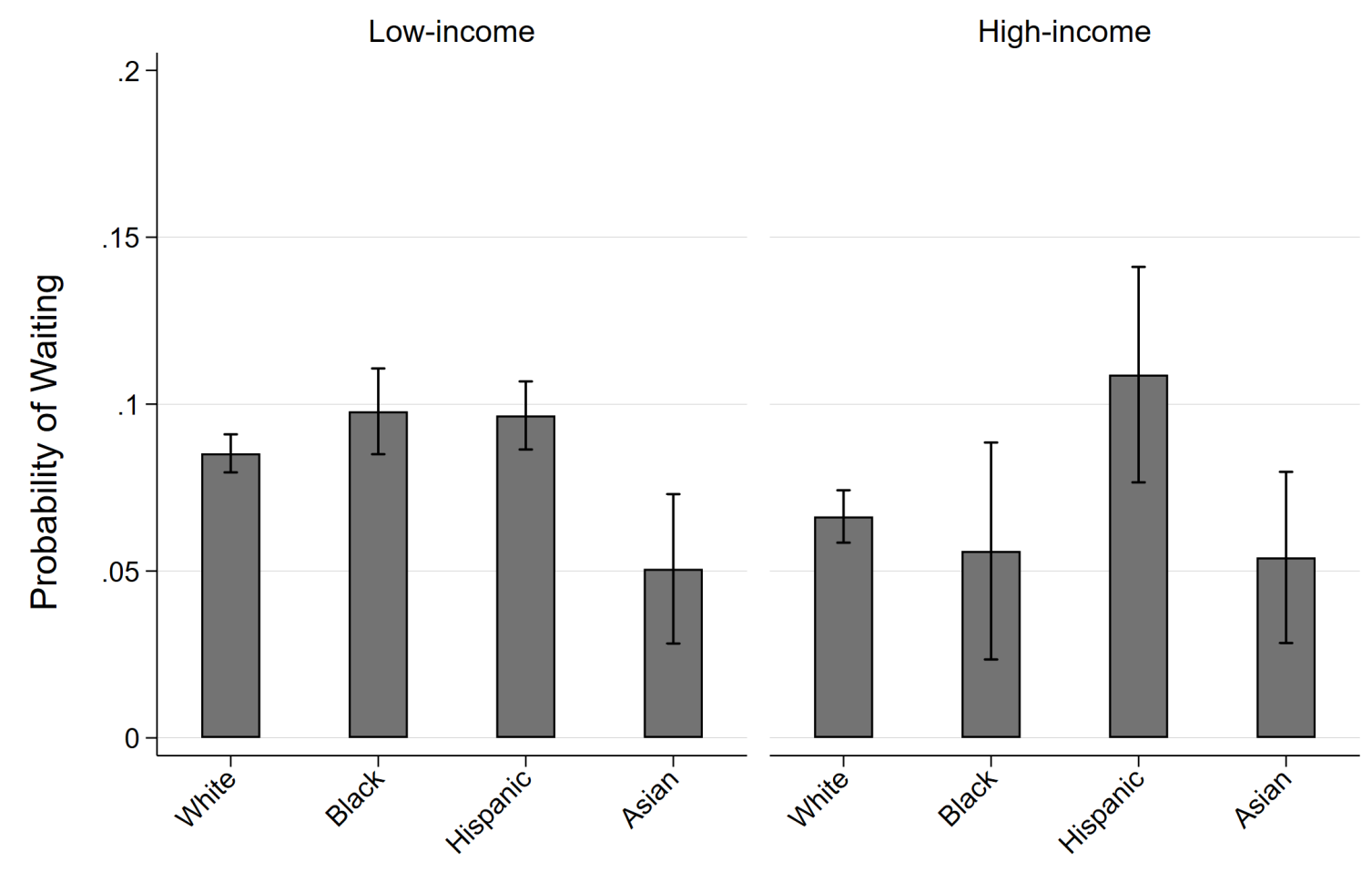

Note: Marginal effects from OLS regressions shown. Includes controls for day of week, month, and year time trends, travel and work time, whether respondent lives in an MSA, unemployment status, and family controls. Weighted using BLS provided weights. $\mathrm{N}=22,252$ for low-income sample and $\mathrm{N}=8,298$ for high-income. 
Figure 7: Time Spent Waiting for Services by Race, With Controls (in minutes; $\mathrm{T} \mid \mathrm{T}>0$; weighted)

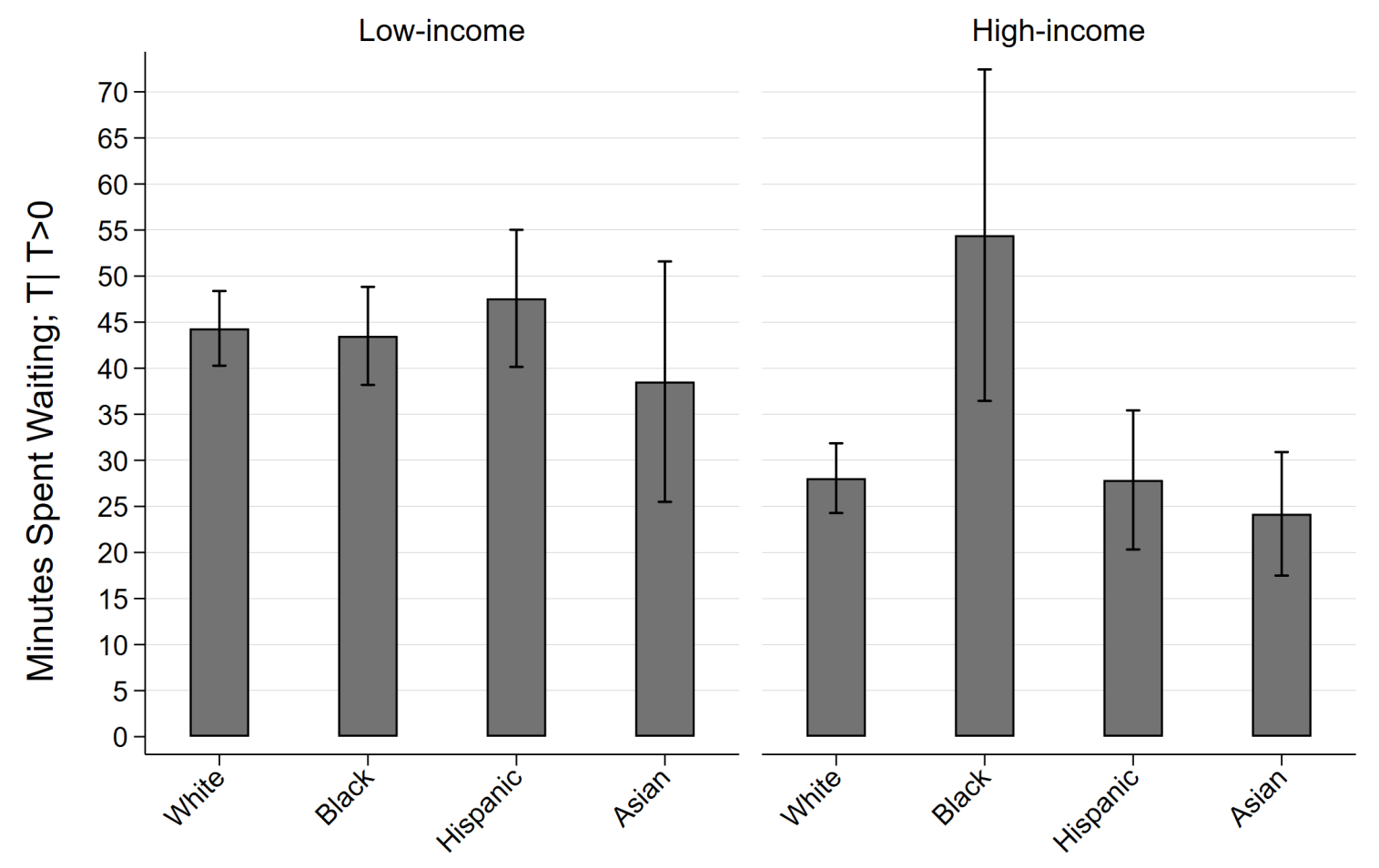

Note: Marginal effects from OLS regressions shown. Includes controls for day of week, month, and year time trends, travel and work time, whether respondent lives in an MSA, unemployment status, and family controls. Weighted using BLS provided weights. $N=2,020$ for low-income sample and $\mathrm{N}=531$ for high-income. 
Figure 8: Probability of Waiting for Service by Time of Day, Weekdays (weighted)

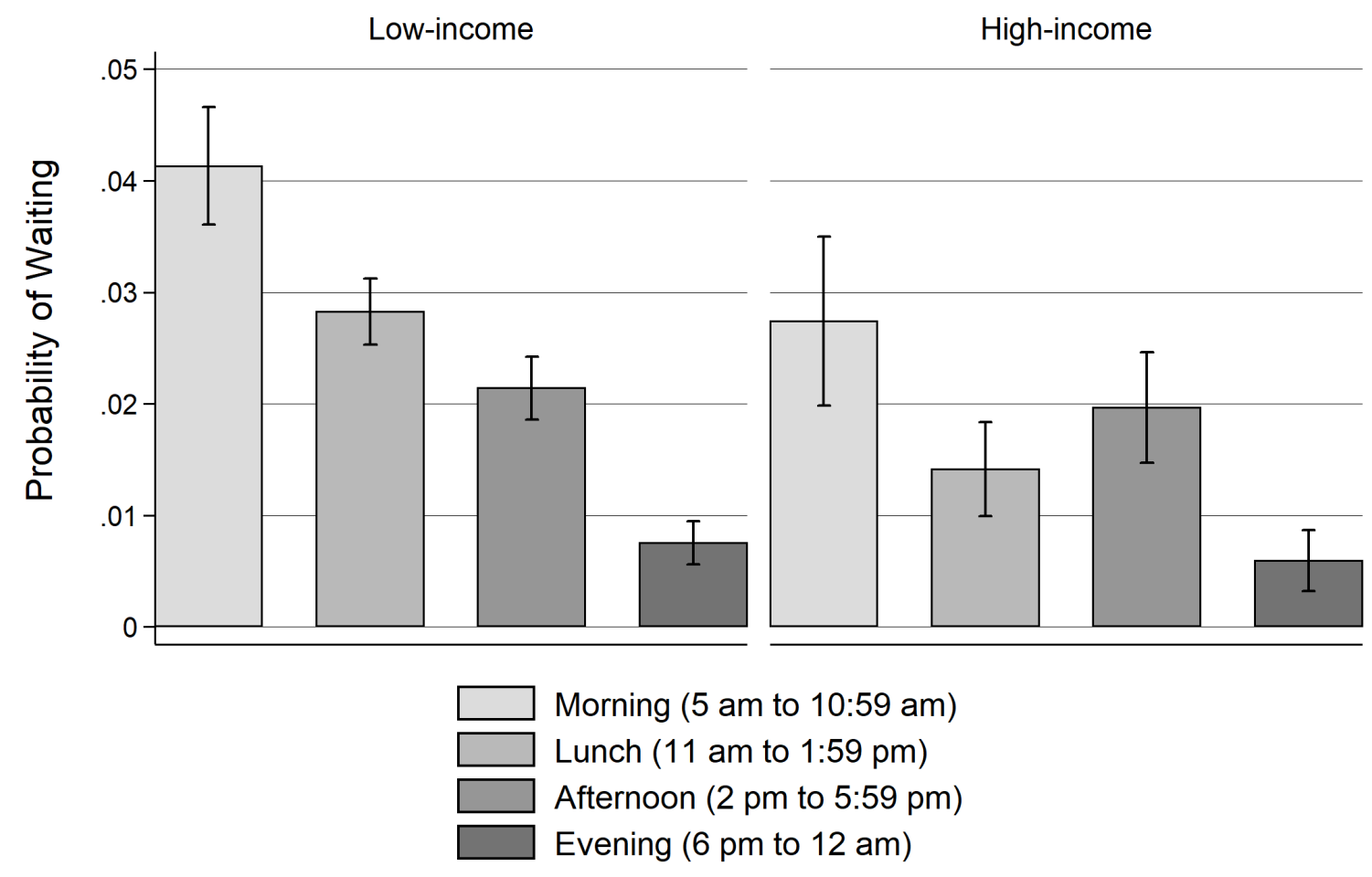

Note: Marginal effects from LPM regressions shown. Includes only controls for month and year time trends. Monday through Friday are considered weekdays. Weighted using BLS provided weights. $\mathrm{N}=12,532$ for low-income sample and $\mathrm{N}=4,082$ for high-income. 
Figure 9: Probability of Waiting for Service by Time of Day, Weekends (weighted)

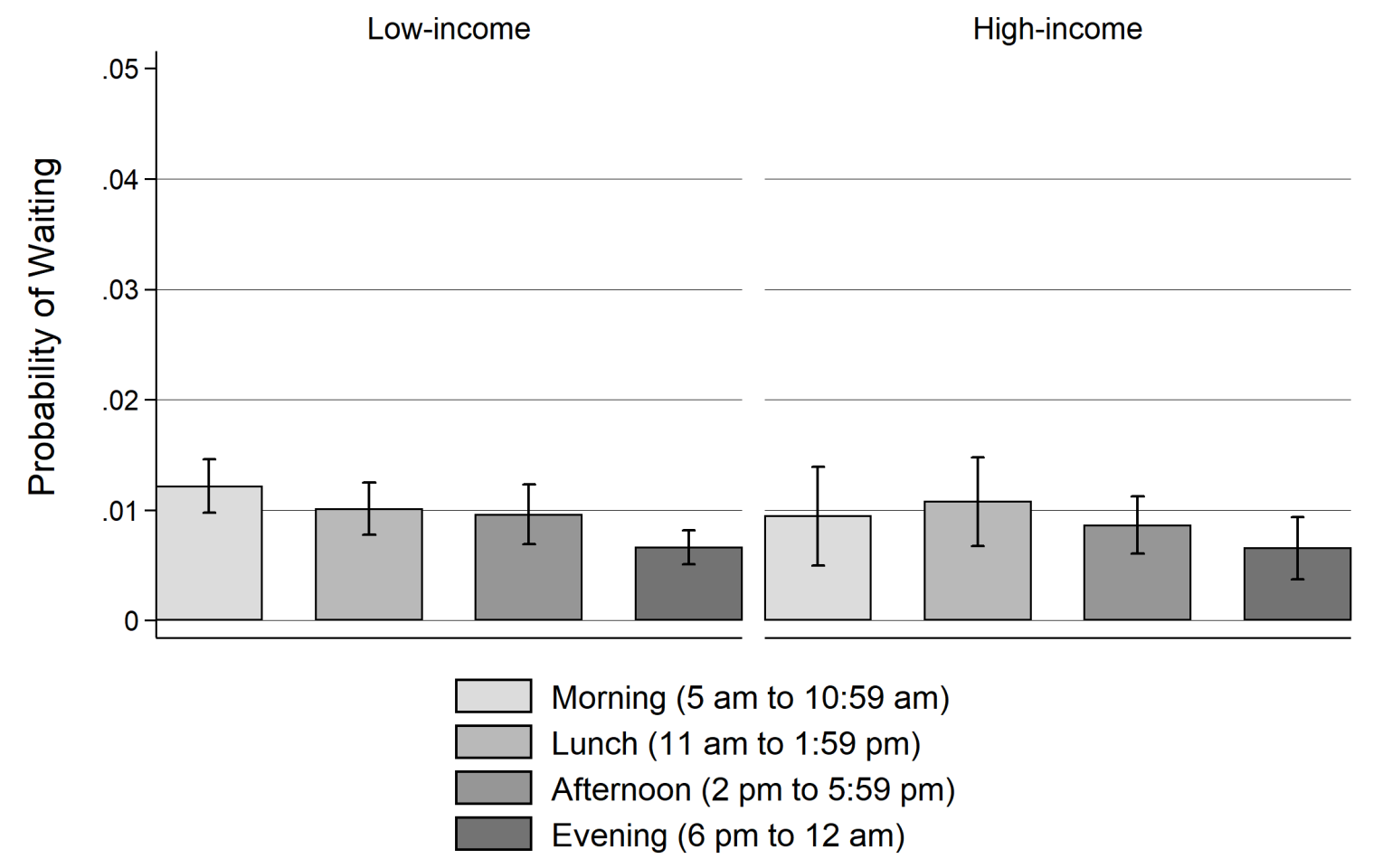

Note: Marginal effects from LPM regressions shown. Includes only controls for month and year time trends. Monday through Friday are considered weekdays. Weighted using BLS provided weights. $\mathrm{N}=10,181$ for low-income sample and $\mathrm{N}=4,328$ for high-income. 
Figure 10: Time Spent Waiting for Services by Time of Day, Weekdays (in minutes; $\mathrm{T} \mid \mathrm{T}$ $>0$; weighted)

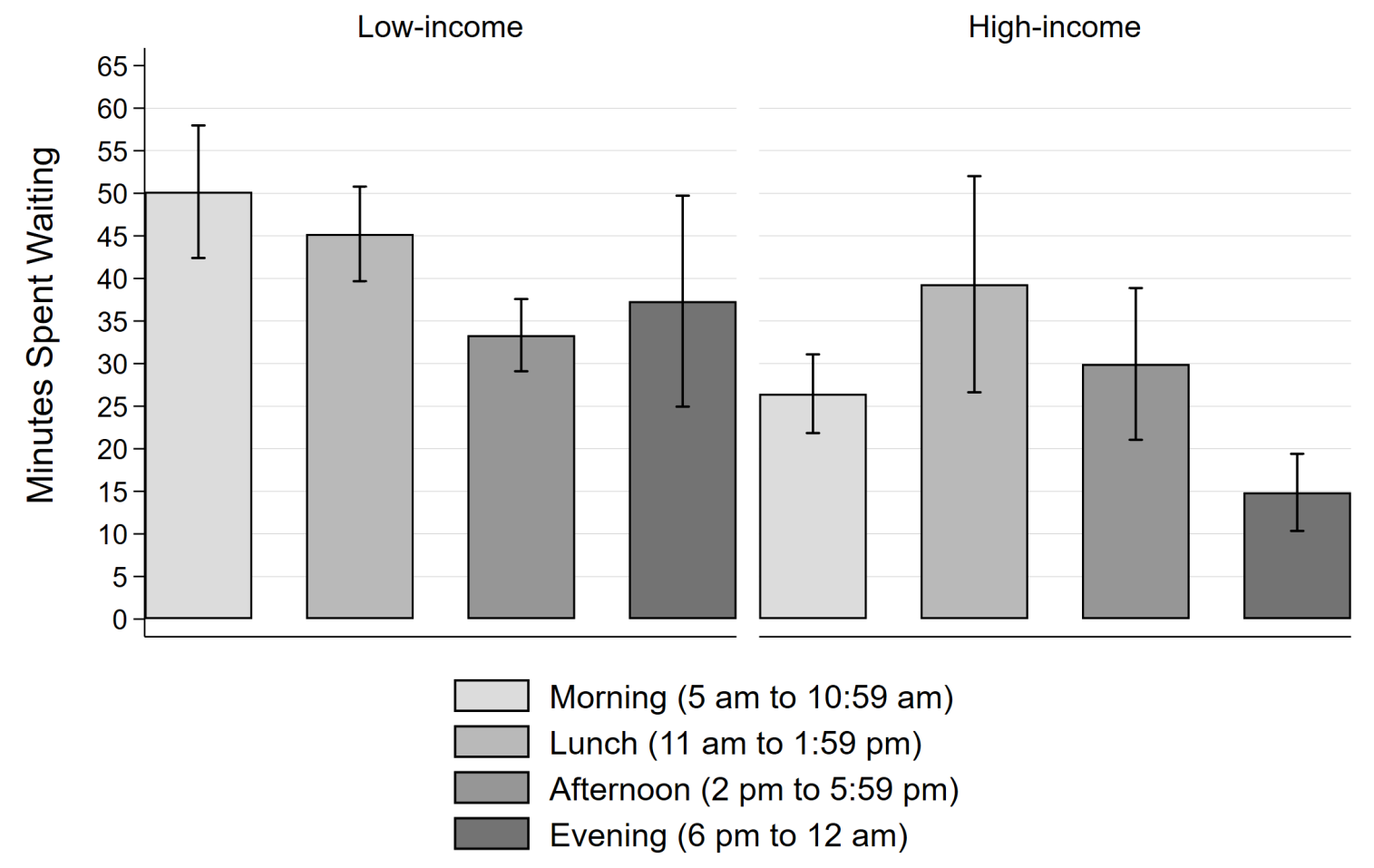

Note: Marginal effects from OLS regressions shown. Includes only controls for month and year time trends. Monday through Friday are considered weekdays. Weighted using BLS provided weights. $\mathrm{N}=1,484$ for low-income sample and $\mathrm{N}=276$ for high-income. 
Figure 11: Time Spent Waiting for Services by Time of Day, Weekends (in minutes; $\mathrm{T} \mid \mathrm{T}$ $>0$; weighted)

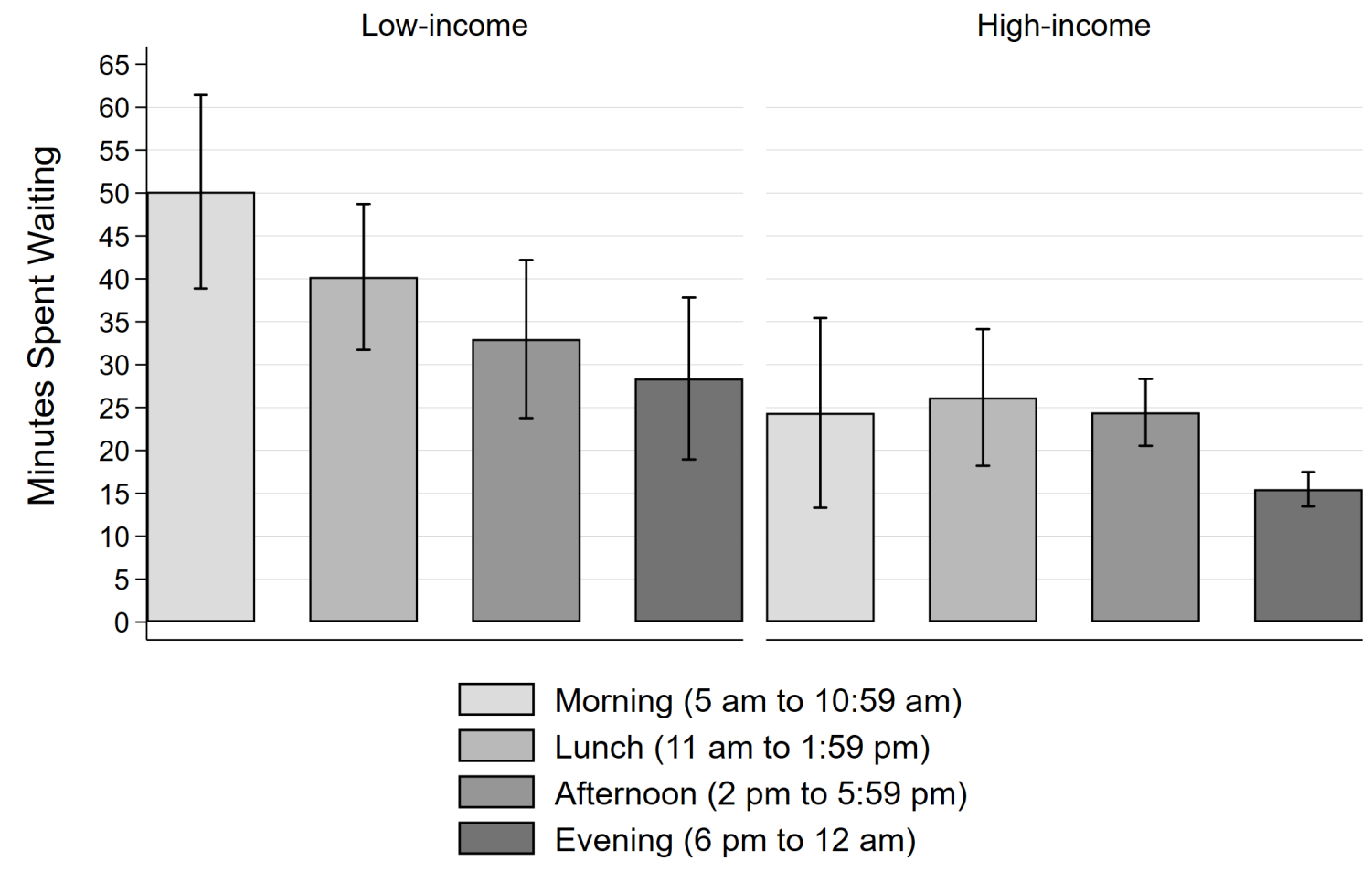

Note: Marginal effects from OLS regressions shown. Includes only controls for month and year time trends. Saturday and Sunday are considered weekdays. Weighted using BLS provided weights. $\mathrm{N}=519$ for low-income sample and $\mathrm{N}=158$ for high-income. 


\section{Appendix A}

Table A.1: OLS estimates of SES gap in waiting time (in minutes), weighted

\begin{tabular}{lccccccc}
\hline \hline & $(1)$ & $(2)$ & $(3)$ & $(4)$ & $(5)$ & $(6)$ & $(7)$ \\
\hline HH income $\$ 150 \mathrm{~K}$ or more & $($ Omitted) & & & & & & \\
HH income $\$ 20 \mathrm{~K}$ or less & $0.99^{* * *}$ & $0.99^{* * *}$ & $1.21^{* * *}$ & $0.79^{* * *}$ & $0.89^{* * *}$ & $0.65^{* * *}$ & $0.37^{* * *}$ \\
& $(0.16)$ & $(0.16)$ & $(0.16)$ & $(0.15)$ & $(0.15)$ & $(0.15)$ & $(0.09)$ \\
& $0.89^{* * *}$ & $0.89^{* * *}$ & $1.09^{* * *}$ & $0.82^{* * *}$ & $0.89^{* * *}$ & $0.68^{* * *}$ & $0.33^{* * *}$ \\
HH income $\$ 20 \mathrm{~K}$ to $\$ 40 \mathrm{~K}$ & $(0.16)$ & $(0.16)$ & $(0.16)$ & $(0.15)$ & $(0.16)$ & $(0.16)$ & $(0.10)$ \\
& $0.66^{* * *}$ & $0.66^{* * *}$ & $0.80^{* * *}$ & $0.66^{* * *}$ & $0.70^{* * *}$ & $0.57^{* * *}$ & $0.31^{* * *}$ \\
HH income $\$ 40 \mathrm{~K}$ to $\$ 60 \mathrm{~K}$ & $(0.15)$ & $(0.15)$ & $(0.16)$ & $(0.15)$ & $(0.16)$ & $(0.16)$ & $(0.11)$ \\
& $0.48^{* * *}$ & $0.48^{* * *}$ & $0.61^{* * *}$ & $0.53^{* * *}$ & $0.55^{* * *}$ & $0.48^{* * *}$ & $0.25^{* *}$ \\
& $(0.16)$ & $(0.17)$ & $(0.17)$ & $(0.17)$ & $(0.17)$ & $(0.17)$ & $(0.12)$ \\
HH income $\$ 60 \mathrm{~K}$ to $\$ 75 \mathrm{~K}$ & $0.44^{* *}$ & $0.44^{* *}$ & $0.56^{* * *}$ & $0.51^{* * *}$ & $0.52^{* * *}$ & $0.48^{* *}$ & $0.31^{* * *}$ \\
& $(0.18)$ & $(0.18)$ & $(0.19)$ & $(0.18)$ & $(0.18)$ & $(0.18)$ & $(0.11)$ \\
HH income $\$ 75 \mathrm{~K}$ to $\$ 100 \mathrm{~K}$ & $0.36^{*}$ & $0.36^{*}$ & $0.42^{* *}$ & $0.42^{* *}$ & $0.42^{* *}$ & $0.41^{* *}$ & 0.18 \\
& $(0.18)$ & $(0.18)$ & $(0.18)$ & $(0.18)$ & $(0.18)$ & $(0.18)$ & $(0.11)$ \\
HH income $\$ 100 \mathrm{~K}$ to $\$ 150 \mathrm{~K}$ & $\checkmark$ & $\checkmark$ & $\checkmark$ & $\checkmark$ & $\checkmark$ & $\checkmark$ & $\checkmark$ \\
Controls for time trends & & $\checkmark$ & $\checkmark$ & $\checkmark$ & $\checkmark$ & $\checkmark$ & $\checkmark$ \\
Controls for MSA & & & $\checkmark$ & $\checkmark$ & $\checkmark$ & $\checkmark$ & $\checkmark$ \\
Controls for travel time & & & & $\checkmark$ & $\checkmark$ & $\checkmark$ & $\checkmark$ \\
Controls for work time & & & & & $\checkmark$ & $\checkmark$ & $\checkmark$ \\
Controls for family & & & & & & $\checkmark$ & $\checkmark$ \\
Controls for demos. \& education & & & & & & & $\checkmark$ \\
Controls for state FE & & & & & & $\checkmark$ \\
\hline Adjusted $R^{2}$ & 210,586 & 210,586 & 210,586 & 210,586 & 210,586 & 210,586 & 210,586 \\
Observations & & & & & $\checkmark$ & $\checkmark$ \\
\hline \hline
\end{tabular}

Note: Robust standard errors clustered at the state-level (in parentheses); ${ }^{*} \mathrm{p}<.10,{ }^{* *} \mathrm{p}<.05,{ }^{* * *} \mathrm{p}<.01$. 
Table A2: Comparison of Estimators of SES Gap in Time Spent Waiting (in minutes), weighted

\begin{tabular}{lcccc}
\hline \hline & $(1)$ & $(2)$ & $(3)$ & $(4)$ \\
& OLS & Tobit & 2-Way Tobit & Poisson \\
\hline HH income $\$ 20 \mathrm{~K}$ or less & $0.65^{* * *}$ & $0.22^{*}$ & $0.18^{* *}$ & $0.49^{* *}$ \\
& $(0.15)$ & $(0.11)$ & $(0.09)$ & $(0.19)$ \\
HH income $\$ 20 \mathrm{~K}$ to $\$ 40 \mathrm{~K}$ & $0.68^{* * *}$ & $0.30^{* *}$ & $0.24^{* *}$ & $0.53^{* * *}$ \\
& $(0.16)$ & $(0.12)$ & $(0.10)$ & $(0.18)$ \\
HH income $\$ 40 \mathrm{~K}$ to $\$ 60 \mathrm{~K}$ & $0.57^{* * *}$ & $0.25^{* *}$ & $0.21^{* *}$ & $0.54^{* * *}$ \\
& $(0.16)$ & $(0.13)$ & $(0.10)$ & $(0.19)$ \\
HH income $\$ 60 \mathrm{~K}$ to $\$ 75 \mathrm{~K}$ & $0.48^{* * *}$ & $0.27^{*}$ & $0.22^{*}$ & $0.43^{*}$ \\
& $(0.17)$ & $(0.15)$ & $(0.12)$ & $(0.23)$ \\
HH income $\$ 75 \mathrm{~K}$ to $\$ 100 \mathrm{~K}$ & $0.48^{* *}$ & $0.30^{* *}$ & $0.22^{* *}$ & $0.49^{* *}$ \\
& $(0.18)$ & $(0.12)$ & $(0.10)$ & $(0.23)$ \\
HH income $\$ 100 \mathrm{~K}$ to $\$ 150 \mathrm{~K}$ & $0.41^{* *}$ & $0.27^{*}$ & $0.21^{*}$ & 0.35 \\
& $(0.18)$ & $(0.16)$ & $(0.13)$ & $(0.25)$ \\
\hline All controls & $\checkmark$ & $\checkmark$ & $\checkmark$ & $\checkmark$ \\
\hline Observations & 210,586 & 210,586 & 210,586 & 210,586 \\
\hline
\end{tabular}

Note: Average partial effects (APE) reported. Standard errors calculated using the delta method; ${ }^{*} \mathrm{p}<.10,{ }^{* *} \mathrm{p}<.05,{ }^{* * *} \mathrm{p}<.01$. 
Table A3: Comparison of Estimators of SES Gap in Time Spent Waiting (in minutes; T | T $>0)$, weighted

\begin{tabular}{lcccc}
\hline \hline & $(1)$ & $(2)$ & $(3)$ & $(4)$ \\
& OLS & Tobit & 2-Way Tobit & Poisson \\
\hline HH income $\$ 150 \mathrm{~K}$ or more & $($ Omitted $)$ & & & \\
HH income $\$ 20 \mathrm{~K}$ or less & $7.34^{* *}$ & $5.49^{* * *}$ & $4.62^{* * *}$ & $8.66^{* * *}$ \\
& $(2.76)$ & $(2.05)$ & $(1.68)$ & $(3.28)$ \\
HH income $\$ 20 \mathrm{~K}$ to $\$ 40 \mathrm{~K}$ & $7.26^{* * *}$ & $5.43^{* * *}$ & $4.53^{* * *}$ & $8.54^{* * *}$ \\
& $(2.68)$ & $(1.99)$ & $(1.52)$ & $(3.24)$ \\
HH income $\$ 40 \mathrm{~K}$ to $\$ 60 \mathrm{~K}$ & $6.82^{* *}$ & $5.10^{* *}$ & $4.17^{* *}$ & $8.38^{* * *}$ \\
& $(2.67)$ & $(1.99)$ & $(1.73)$ & $(3.05)$ \\
HH income $\$ 60 \mathrm{~K}$ to $\$ 75 \mathrm{~K}$ & 3.31 & 2.48 & 1.71 & 4.98 \\
& $(3.25)$ & $(2.43)$ & $(2.11)$ & $(3.80)$ \\
HH income $\$ 75 \mathrm{~K}$ to $\$ 100 \mathrm{~K}$ & 4.82 & 3.61 & 1.05 & 6.50 \\
& $(3.83)$ & $(2.85)$ & $(1.84)$ & $(4.53)$ \\
HH income $\$ 100 \mathrm{~K}$ to $\$ 150 \mathrm{~K}$ & 2.75 & 2.06 & 1.24 & 4.05 \\
& $(2.98)$ & $(2.22)$ & $(1.86)$ & $(3.80)$ \\
\hline All controls & $\checkmark$ & $\checkmark$ & $\checkmark$ & $\checkmark$ \\
\hline Observations & 8,363 & 8,363 & 8,363 & 8,363 \\
\hline
\end{tabular}

Note: Average partial effects (APE) reported. Standard errors calculated using the delta method; ${ }^{*} \mathrm{p}<.10,{ }^{* *} \mathrm{p}<.05,{ }^{* * *} \mathrm{p}<.01$. 
Table A4: Tobit estimates of SES gap in waiting time (in minutes), weighted

\begin{tabular}{|c|c|c|c|c|c|c|c|}
\hline & $(1)$ & $(2)$ & $(3)$ & $(4)$ & $(5)$ & $(6)$ & $(7)$ \\
\hline HH income $\$ 150 \mathrm{~K}$ or more & (Omitted) & & & & & & \\
\hline HH income $\$ 20 \mathrm{~K}$ or less & $\begin{array}{c}0.69^{* * *} \\
(0.12)\end{array}$ & $\begin{array}{c}0.72^{* * *} \\
(0.12)\end{array}$ & $\begin{array}{c}0.80^{* * *} \\
(0.12)\end{array}$ & $\begin{array}{c}0.34^{* * *} \\
(0.11)\end{array}$ & $\begin{array}{c}0.35^{* * *} \\
(0.11)\end{array}$ & $\begin{array}{c}0.22^{*} \\
(0.11)\end{array}$ & $\begin{array}{c}0.22^{*} \\
(0.11)\end{array}$ \\
\hline $\mathrm{HH}$ income $\$ 20 \mathrm{~K}$ to $\$ 40 \mathrm{~K}$ & $\begin{array}{c}0.58^{* * *} \\
(0.12)\end{array}$ & $\begin{array}{c}0.60^{* * *} \\
(0.12)\end{array}$ & $\begin{array}{c}0.72^{* * *} \\
(0.13)\end{array}$ & $\begin{array}{c}0.40^{* * *} \\
(0.12)\end{array}$ & $\begin{array}{c}0.40^{* * *} \\
(0.12)\end{array}$ & $\begin{array}{l}0.30^{* *} \\
(0.12)\end{array}$ & $\begin{array}{l}0.30^{* *} \\
(0.12)\end{array}$ \\
\hline HH income $\$ 40 \mathrm{~K}$ to $\$ 60 \mathrm{~K}$ & $\begin{array}{c}0.40^{* * *} \\
(0.15)\end{array}$ & $\begin{array}{c}0.42^{* * *} \\
(0.15)\end{array}$ & $\begin{array}{c}0.49^{* * *} \\
(0.14)\end{array}$ & $\begin{array}{l}0.33^{* *} \\
(0.13)\end{array}$ & $\begin{array}{l}0.32^{* *} \\
(0.13)\end{array}$ & $\begin{array}{l}0.25^{* *} \\
(0.13)\end{array}$ & $\begin{array}{l}0.25^{* *} \\
(0.13)\end{array}$ \\
\hline HH income $\$ 60 \mathrm{~K}$ to $\$ 75 \mathrm{~K}$ & $\begin{array}{l}0.34^{* *} \\
(0.15)\end{array}$ & $\begin{array}{l}0.36^{* *} \\
(0.15)\end{array}$ & $\begin{array}{c}0.43^{* * *} \\
(0.15)\end{array}$ & $\begin{array}{l}0.33^{* *} \\
(0.15)\end{array}$ & $\begin{array}{l}0.32^{\text {** }} \\
(0.15)\end{array}$ & $\begin{array}{l}0.27^{*} \\
(0.15)\end{array}$ & $\begin{array}{l}0.27^{*} \\
(0.15)\end{array}$ \\
\hline HH income $\$ 75 \mathrm{~K}$ to $\$ 100 \mathrm{~K}$ & $\begin{array}{l}0.30^{* *} \\
(0.13)\end{array}$ & $\begin{array}{l}0.31^{* *} \\
(0.13)\end{array}$ & $\begin{array}{c}0.39^{* * *} \\
(0.12)\end{array}$ & $\begin{array}{c}0.34^{* * *} \\
(0.12)\end{array}$ & $\begin{array}{c}0.33^{* * *} \\
(0.12)\end{array}$ & $\begin{array}{l}0.30^{* *} \\
(0.12)\end{array}$ & $\begin{array}{l}0.30^{* *} \\
(0.12)\end{array}$ \\
\hline HH income $\$ 100 \mathrm{~K}$ to $\$ 150 \mathrm{~K}$ & $\begin{array}{c}0.27 \\
(0.18) \\
\end{array}$ & $\begin{array}{c}0.28 \\
(0.18) \\
\end{array}$ & $\begin{array}{l}0.30^{*} \\
(0.17)\end{array}$ & $\begin{array}{c}0.29^{*} \\
(0.16)\end{array}$ & $\begin{array}{l}0.28^{*} \\
(0.16)\end{array}$ & $\begin{array}{l}0.27^{*} \\
(0.16)\end{array}$ & $\begin{array}{l}0.27^{*} \\
(0.16)\end{array}$ \\
\hline Controls for time trends & $\checkmark$ & $\checkmark$ & $\checkmark$ & $\checkmark$ & $\checkmark$ & $\checkmark$ & $\checkmark$ \\
\hline Controls for MSA & & $\checkmark$ & $\checkmark$ & $\checkmark$ & $\checkmark$ & $\checkmark$ & $\checkmark$ \\
\hline Controls for travel time & & & $\checkmark$ & $\checkmark$ & $\checkmark$ & $\checkmark$ & $\checkmark$ \\
\hline Controls for work time & & & & $\checkmark$ & $\checkmark$ & $\checkmark$ & $\checkmark$ \\
\hline Controls for family & & & & & $\checkmark$ & $\checkmark$ & $\checkmark$ \\
\hline Controls for demographics & & & & & & $\checkmark$ & $\checkmark$ \\
\hline Controls for education and unemployment & & & & & & & $\checkmark$ \\
\hline Observations & 210,586 & 210,586 & 210,586 & 210,586 & 210,586 & 210,586 & 210,586 \\
\hline
\end{tabular}

Note: Average partial effects (APE) reported. Standard errors calculated using the delta method; ${ }^{*} \mathrm{p}<.10,{ }^{* *} \mathrm{p}<.05,{ }^{* * *} \mathrm{p}<$ .01. 
Table A5: OLS estimates of SES Gap in Time Spent Waiting Conditional on Non-Zero Time in Associated Activities (in minutes), weighted

\begin{tabular}{lccccccc}
\hline \hline & $(1)$ & $(2)$ & $(3)$ & $(4)$ & $(5)$ & $(6)$ & $(7)$ \\
\hline HH income $\$ 150 \mathrm{~K}$ or more & $($ Omitted) & & & & & & \\
HH income $\$ 20 \mathrm{~K}$ or less & $1.87^{* * *}$ & $1.88^{* * *}$ & $1.96^{* * *}$ & $1.53^{* * *}$ & $1.65^{* * *}$ & $1.19^{* * *}$ & $0.73^{* * *}$ \\
& $(0.23)$ & $(0.23)$ & $(0.24)$ & $(0.22)$ & $(0.22)$ & $(0.21)$ & $(0.14)$ \\
& $1.58^{* * *}$ & $1.59^{* * *}$ & $1.71^{* * *}$ & $1.42^{* * *}$ & $1.49^{* * *}$ & $1.08^{* * *}$ & $0.43^{* *}$ \\
HH income $\$ 20 \mathrm{~K}$ to $\$ 40 \mathrm{~K}$ & $(0.28)$ & $(0.27)$ & $(0.28)$ & $(0.27)$ & $(0.28)$ & $(0.26)$ & $(0.17)$ \\
& $1.12^{* * *}$ & $1.12^{* * *}$ & $1.20^{* * *}$ & $1.09^{* * *}$ & $1.12^{* * *}$ & $0.88^{* * *}$ & $0.37^{* *}$ \\
HH income $\$ 40 \mathrm{~K}$ to $\$ 60 \mathrm{~K}$ & $(0.28)$ & $(0.28)$ & $(0.28)$ & $(0.27)$ & $(0.27)$ & $(0.27)$ & $(0.18)$ \\
& $0.71^{* * *}$ & $0.71^{* * *}$ & $0.80^{* * *}$ & $0.75^{* * *}$ & $0.77^{* * *}$ & $0.61^{* *}$ & 0.22 \\
& $(0.24)$ & $(0.24)$ & $(0.25)$ & $(0.25)$ & $(0.24)$ & $(0.25)$ & $(0.20)$ \\
HH income $\$ 60 \mathrm{~K}$ to $\$ 75 \mathrm{~K}$ & $0.61^{* *}$ & $0.61^{* *}$ & $0.73^{* * *}$ & $0.71^{* * *}$ & $0.71^{* * *}$ & $0.62^{* *}$ & $0.38^{* *}$ \\
& $(0.25)$ & $(0.25)$ & $(0.25)$ & $(0.25)$ & $(0.25)$ & $(0.25)$ & $(0.16)$ \\
HH income $\$ 75 \mathrm{~K}$ to $\$ 100 \mathrm{~K}$ & $0.68^{* *}$ & $0.68^{* *}$ & $0.74^{* *}$ & $0.77^{* *}$ & $0.75^{* *}$ & $0.72^{* *}$ & $0.34^{* *}$ \\
& $(0.29)$ & $(0.30)$ & $(0.30)$ & $(0.30)$ & $(0.30)$ & $(0.30)$ & $(0.17)$ \\
HH income $\$ 100 \mathrm{~K}$ to $\$ 150 \mathrm{~K}$ & $\checkmark$ & $\checkmark$ & $\checkmark$ & $\checkmark$ & $\checkmark$ & $\checkmark$ & $\checkmark$ \\
& & $\checkmark$ & $\checkmark$ & $\checkmark$ & $\checkmark$ & $\checkmark$ & $\checkmark$ \\
Controls for time trends & & & $\checkmark$ & $\checkmark$ & $\checkmark$ & $\checkmark$ & $\checkmark$ \\
Controls for MSA & & & & $\checkmark$ & $\checkmark$ & $\checkmark$ & $\checkmark$ \\
Controls for travel time & & & & & $\checkmark$ & $\checkmark$ & $\checkmark$ \\
Controls for work time & & & & & & $\checkmark$ & $\checkmark$ \\
Controls for family & & & & & & & $\checkmark$ \\
Controls for demos. \& education & & 0.00 & 0.02 & 0.02 & 0.02 & 0.02 & 0.02 \\
Controls for state FE & 107,749 & 107,749 & 107,749 & 107,749 & 107,749 & 107,749 & 107,749 \\
\hline Adjusted $R^{2}$ & & & & $\checkmark$ & $\checkmark$ \\
Observations & & & & & $\checkmark$ & $\checkmark$ \\
\hline \hline
\end{tabular}

Note: Robust standard errors clustered at the state-level (in parentheses); ${ }^{*} \mathrm{p}<.10,{ }^{* *} \mathrm{p}<.05,{ }^{* * *} \mathrm{p}<.01$. 
Table A6: Logistic regression estimates of likelihood for no waiting time for services, weighted

\begin{tabular}{|c|c|c|c|c|c|c|c|}
\hline & (1) & $(2)$ & $(3)$ & $(4)$ & $(5)$ & (6) & (7) \\
\hline HH income $\$ 150 \mathrm{~K}$ or more & (Omitted) & & & & & & \\
\hline HH income $\$ 20 \mathrm{~K}$ or less & $\begin{array}{c}-0.03^{* * *} \\
(0.00)\end{array}$ & $\begin{array}{c}-0.03^{* * *} \\
(0.00)\end{array}$ & $\begin{array}{c}-0.03^{* * *} \\
(0.00)\end{array}$ & $\begin{array}{c}-0.02^{* * *} \\
(0.00)\end{array}$ & $\begin{array}{c}-0.02^{* * *} \\
(0.00)\end{array}$ & $\begin{array}{c}-0.01^{* * *} \\
(0.00)\end{array}$ & $\begin{array}{c}-0.01^{* * *} \\
(0.00)\end{array}$ \\
\hline HH income $\$ 20 \mathrm{~K}$ to $\$ 40 \mathrm{~K}$ & $\begin{array}{c}-0.02^{* * *} \\
(0.00)\end{array}$ & $\begin{array}{c}-0.02^{* * *} \\
(0.00)\end{array}$ & $\begin{array}{c}-0.02^{* * *} \\
(0.00)\end{array}$ & $\begin{array}{c}-0.01^{* * *} \\
(0.00)\end{array}$ & $\begin{array}{c}-0.01^{* * *} \\
(0.00)\end{array}$ & $\begin{array}{c}-0.01^{* *} \\
(0.00)\end{array}$ & $\begin{array}{c}-0.01^{* *} \\
(0.00)\end{array}$ \\
\hline HH income $\$ 40 \mathrm{~K}$ to $\$ 60 \mathrm{~K}$ & $\begin{array}{c}-0.01^{* * *} \\
(0.00)\end{array}$ & $\begin{array}{c}-0.01^{* * *} \\
(0.00)\end{array}$ & $\begin{array}{c}-0.01^{* * *} \\
(0.00)\end{array}$ & $\begin{array}{c}-0.01^{* *} \\
(0.00)\end{array}$ & $\begin{array}{c}-0.01^{* *} \\
(0.00)\end{array}$ & $\begin{array}{l}-0.01 \\
(0.00)\end{array}$ & $\begin{array}{l}-0.01 \\
(0.00)\end{array}$ \\
\hline $\mathrm{HH}$ income $\$ 60 \mathrm{~K}$ to $\$ 75 \mathrm{~K}$ & $\begin{array}{c}-0.01^{* *} \\
(0.01)\end{array}$ & $\begin{array}{c}-0.01^{* *} \\
(0.01)\end{array}$ & $\begin{array}{c}-0.01^{* *} \\
(0.01)\end{array}$ & $\begin{array}{l}-0.01^{*} \\
(0.01)\end{array}$ & $\begin{array}{l}-0.01^{*} \\
(0.01)\end{array}$ & $\begin{array}{l}-0.01 \\
(0.01)\end{array}$ & $\begin{array}{l}-0.01 \\
(0.01)\end{array}$ \\
\hline HH income $\$ 75 \mathrm{~K}$ to $\$ 100 \mathrm{~K}$ & $\begin{array}{l}-0.01^{*} \\
(0.00)\end{array}$ & $\begin{array}{l}-0.01^{*} \\
(0.00)\end{array}$ & $\begin{array}{c}-0.01^{* *} \\
(0.00)\end{array}$ & $\begin{array}{c}-0.01^{* *} \\
(0.00)\end{array}$ & $\begin{array}{c}-0.01^{* *} \\
(0.00)\end{array}$ & $\begin{array}{l}-0.01^{*} \\
(0.00)\end{array}$ & $\begin{array}{l}-0.01^{*} \\
(0.00)\end{array}$ \\
\hline $\mathrm{HH}$ income $\$ 100 \mathrm{~K}$ to $\$ 150 \mathrm{~K}$ & $\begin{array}{l}-0.01^{*} \\
(0.01)\end{array}$ & $\begin{array}{l}-0.01^{*} \\
(0.01)\end{array}$ & $\begin{array}{l}-0.01^{*} \\
(0.01)\end{array}$ & $\begin{array}{l}-0.01^{*} \\
(0.00)\end{array}$ & $\begin{array}{l}-0.01^{*} \\
(0.00)\end{array}$ & $\begin{array}{l}-0.01^{*} \\
(0.00)\end{array}$ & $\begin{array}{l}-0.01^{*} \\
(0.00)\end{array}$ \\
\hline Controls for time trends & $\checkmark$ & $\checkmark$ & $\checkmark$ & $\checkmark$ & $\checkmark$ & $\checkmark$ & $\checkmark$ \\
\hline Controls for MSA & & $\checkmark$ & $\checkmark$ & $\checkmark$ & $\checkmark$ & $\checkmark$ & $\checkmark$ \\
\hline Controls for travel time & & & $\checkmark$ & $\checkmark$ & $\checkmark$ & $\checkmark$ & $\checkmark$ \\
\hline Controls for work time & & & & $\checkmark$ & $\checkmark$ & $\checkmark$ & $\checkmark$ \\
\hline Controls for family & & & & & $\checkmark$ & $\checkmark$ & $\checkmark$ \\
\hline Controls for demographics & & & & & & $\checkmark$ & $\checkmark$ \\
\hline Controls for education and unemployment & & & & & & & $\checkmark$ \\
\hline Observations & 107,749 & 107,749 & 107,749 & 107,749 & 107,749 & 107,749 & 107,749 \\
\hline
\end{tabular}

Note: A $\overline{\overline{\text { verage partial effects (APE) reported. Standard errors calculated using the delta method; }{ }^{*} \mathrm{p}<.10,{ }^{* *} \mathrm{p}<.05,{ }^{* * *} \mathrm{p}}<}$ .01 . 
Figure 12: Probability of Using Services, No Controls (weighted)

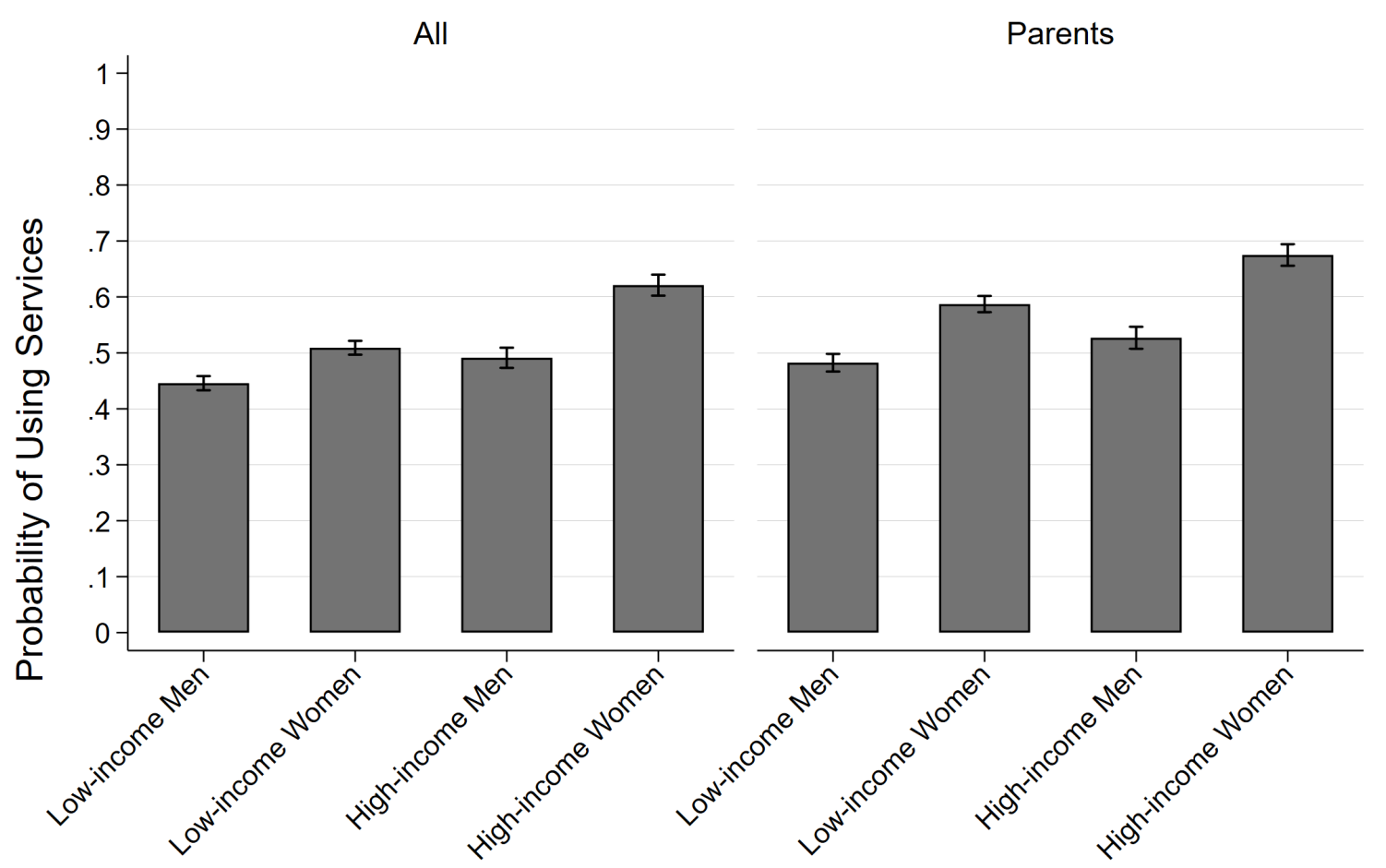

Note: Marginal effects from OLS regressions shown. Includes only controls for day of week, month, and year time trends. Includes all observations, including those with zero waiting time. Parents includes only respondents with at least one household child 17 years old or younger. Weighted using BLS provided weights. $\mathrm{N}=64,540$ for All sample and $\mathrm{N}=26,585$ for parents. 